\title{
s-Process Studies in the Light of New Experimental Cross Sections: Distribution of Neutron Fluences and r-Process Residuals
}

\author{
F. Käppeler, H. Beer, K. Wisshak, D. D. Clayton, \\ R. L. Macklin, R. A. Ward \\ Institut für Angewandte Kernphysik
}

\section{Kernforschungszentrum Karlsruhe}





\section{KERNFORSCHUNGSZENTRUM KARLSRUHE}

Institut für Angewandte Kernphysik

KfK 3210

s-Process Studies in the Light of New Experimental

Cross Sections: Distribution of Neutron Fluences and $\underline{r}$-Process Residuals

F. Käppeler, H. Beer, K. Wisshak, D.D. Clayton*, R.L. Mack1in** and R.A. Ward***

* Max-Planck-Institut für Kernphysik, Heidelberg and Rice University, Houston, Texas, USA

** Oak Ridge National Laboratory, Oak Ridge, Tenn., USA

*** Max-P1anck-Institut für Physik und Astrophysik, München 
Als Manuskript vervielfältigt

Für diesen Bericht behalten wir uns alle Rechte vor

Kernforschungszentrum Karlsruhe $\mathrm{GmbH}$

ISSN 0303-4003 
A best set of neutron-capture cross sections has been evaluated for the most important s-process isotopes. With this data base, s-process studies have been carried out using the traditional model which assumes a steady neutron flux and an exponential distribution of neutron irradiations. The calculated $\sigma \mathrm{N}$-curve is in excellent agreement with the empirical oN-values of pure s-process nuclei. Simultaneously, good agreement is found between the difference of solar and s-process abundances and the abundances of pure $\underline{r}$-process nuclei. We also discuss the abundance pattern of the iron group elements where our s-process results complement the abundances obtained from explosive nuclear burning. The results obtained from the traditional s-process model such as seed abundances, mean neutron irradiations, or neutron densities are compared to recent stellar model calculations which assume the He-burning shells of red giant stars as the site for the s-process.

Untersuchungen zum s-Prozeß mit neuen experimentellen Querschnitten: Die Verteilung der Neutronenfluenz und r-Prozeß Häufigkeiten.

\section{ZUSAMMENFASSUNG}

Für die wichtigsten s-Prozeß Isotope wurde ein bester Satz von Neutroneneinfangquerschnitten zusammengeste11t. Mit diesen Daten wurden Rechnungen zum s-Prozeß mit Hilfe des traditionellen Mode1ls ausgefüht, für das ein stetiger Neutronenfluß und eine exponentielle Verteilung von Neutronenbestrahlungen angenommen wird. Die berechnete $\sigma \mathrm{N}-$ Kurve stimmt sehr gut mit den empirischen oN-Werten der reinen s-Prozeßkerne überein. Gleichzeitig findet man auch gute übereinstimmung zwischen der Differenz von solaren und s-Prozeß-Häufigkeiten und den Häufigkeiten der reinen s-Prozeß-Isotope. Wir diskutieren außerdem das Häufigkeitsmuster der Elemente in der Eisengruppe, wo unsere s-Prozeß-Ergebnisse die Häufigkeiten ergänzen, die man für explosive Kernsynthese abgeleitet hat. Die mit dem traditionellen s-Prozeß Model1 gewonnenen Ergebnisse, wie Saathäufigkeiten, mittlere Neutronenbestrahlungen oder Neutronendichten werden mit neueren Sternmodel1rechnungen verglichen, welche die HeSchale in Roten Riesen Sternen als Ort für den s-Prozeß annehmen. 


\section{INTRODUCTION}

Our primary purposes in this work are to update two basic features of the nucleosynthesis of the elements heavier than iron: (1) the distribution of neutron fluences to which Fe-seed nuclei have been exposed in the slowneutron-capture (s) process, and (2) the abundances to be ascribed to rapidneutron-capture (r) processes. We follow Seeger, Fowler and Clayton (1965), who advocated two procedures to this end: (1) a smooth exponential decline of the numbers of seeds exposed to increasing fluences models the ledgeprecipice structure of the oN curve and is phyiscally plausible in stellar remixing mode1s and.(2) the abundances $\mathrm{N}_{\mathrm{r}}$ of neutron-rich unshielded isobars are evaluated as the differences between the observed abundances and the s-process contribution (if any) indicated by the computed oN curve resulting from (1). The results provide concise targets for the chemical evolution of the Galaxy and for the stellar models of the nucleosynthesis.

One reason for doing this now is that accurate values for several of the sma11 cross sections of nuclei with magic neutron numbers became avai1able recently (Beer and Käppeler 1980) which dominate considerations of the fluence distribution $\rho(\tau)$ (C1ayton et a1. 1961; Seeger et a1. 1965). Also, various measurements of other relevant capture cross sections - e.g. on those nuclei on the $\underline{s}$-process path which are shielded against $\underline{\text { r-process }}$ contributions - have been carried out in recent years. Over the last decade, the experimental techniques for neutron capture cross section measurements have been improved considerably so that uncertainties of typically 5 to $10 \%$ can be achieved in most cases. It should be noted that now the accuracy of cross section data is comparable to that which is quoted for solar system abundances. Altogether, this provides a much better data base than was available for previous investigations.

Another reason is, that in a time of many new computational approaches to both the $\underline{s}-$ and $\underline{r}-$ processes, the fluence distribution remains an almost model-invariant requirement of stellar and galactic evolution, while the detailed $\mathrm{N}_{\mathrm{r}}$ curve shows the structure that must be achieved by its proposed models. The 1ikelihood that the s-process is pulsed (U1rich 1973; Iben 1975a,b) and the corresponding computations in the branchings and in the abundances (Ward et a1. 1976; Truran and Iben 1977; Ward 1977; Iben and Truran 1978; Ward and Newman 1978; Cosner et a1. 1980) do not substantially affect the flux distribution $\rho(\tau)$ despite large changes in temperature-time-scale estimates. This simplification occurs because 
the capture flow must still pass through the neutron-magic nuclei whose smal1 cross sections dominate $\rho(\tau)$ and because the total number of nuclei synthesized is little affected by realistic branching solutions. Flux distributions from physically different $\underline{s}$-processes can even be approximately summed after temperature-scaling of the cross sections to a common reference (Clayton 1968), which we here take to be $\mathrm{kT}=30 \mathrm{keV}$, as usual. Therefore, we will take the steady, traditionally-branched (Ward et al. 1976) s-process at $30 \mathrm{keV}$ as our numerical point of reference. Specific cases of $\underline{r}$-abundances are of course greatly influenced by the details of the pulses (if appropriate). Our resulting $\mathrm{N}_{\mathrm{r}}$ curve will therefore represent a possible sum of many effects, since only the traditional s-process will be subtracted from the totals, but may nevertheless be very useful as a guide in interpreting a possibly wide range of isotopic anomalies.

\section{EXPERIMENTAL QUANTITIES}

\section{a) Abundances}

A quantitative decomposition of heavy-nucleus abundances into nucleosynthesis mechanisms requires a set of relative abundances of those species. Indeed, it was the Suess and Urey (1956) abundance table that stimulated the construction of nucleosynthesis mechanisms. However, this task remains frought with problems, both of sampling and understanding. Different bodies contain different mixtures of the elements, although their isotopic composition is sufficiently uniform as to be virtually exact for this purpose. Because the details of the origin of distinct bodies are unknown, it has been impossible to specify the relationship of their composition to that of the bulk solar system. Even the popular assumption that primitive meteorites yield the best relative abundances of heavy nonvolatile elements is not adequate, because the different classes have various compositions, differing quite frequently by a factor of two.

We will numerically adopt Cameron's (1981) table of natural abundances. It is based primarily on the relative abundances of type $\mathrm{C} 1$ carbonaceous me-teorites, and differs only for a few elements from his previous influential compilation (Cameron 1973). In these works and their references one finds motivations for the choice of $\mathrm{C} 1$ abundances, largely because they seem to compare best to those in the sun (when those are well measured). This specific choice has the advantage of freeing us to concentrate on the nuclear data and the theory without the perhaps circular bias of choosing our own abundance 
data. Nonetheless, one must bear in mind that this choice may be inappropriate, especially for some elements. We will call attention later to a few such questions. This is an iterative science to some degree, and one may also expect the theory to eventually he1p decide how different meteorite classes have been chemically fractionated, thereby helping to understand both their origin and the correct bulk abundance ratios upon which the whole analysis depends.

b) Maxwe11ian Average Cross Sections

(i) Experimenta1 Techniques

In the neutron energy range of interest to s-process nucleosynthesis $\left(1<\mathrm{E}_{\mathrm{n}}<300 \mathrm{keV}\right)$, capture cross sections can be measured with different techniques and different types of neutron sources. It might be worthwhile to outline briefly the general features of the various techniques with emphasis on the respective characteristics and to refer the reader to more specific literature.

Neutrons in the keV range are most efficiently produced by accelerators. Basically, there are electron 1inear accelerators (LINAC) and Van de Graaffaccelerators (VdG) which are most frequently used for this type of work and which both have specific advantages.

A LINAC, such as ORELA in Oak Ridge, provides a very powerful neutron source. Intense neutron bursts with a broad energy distribution are produced by pulsed high power electron beams via $(\gamma, n)$-reactions on heavy metal targets. Repetition rates are typically $1 \mathrm{kHz}$ and pulse widths are a few ns. With this time structure, capture cross section measurements can be carried out with excellent resolution in neutron energy using the time-of-flight (TOF) technique in combination with flight paths of about $50 \mathrm{~m}$. The intense bremsstrahlung from the neutron target requires heavy shielding of the target area, thereby eliminating flight paths shorter than $10 \mathrm{~m}$ and putting certain 1imitations on the maximum solid angle. But in general this is not a severe constraint as the high neutron source strength provides a sufficient neutron flux in the experimental area. This kind of neutron source has been used extensively for capture cross section measurements. Detailed descriptions are given by Macklin and Allen (1971) and in many publications of Macklin et al. (see also the references in this paper).

In contrast to a LINAC, Van de Graaff accelerators are much smaller and their maximum neutron source strength is less by 3 to 4 orders of magnitude. However, because ion beams are used for neutron production, the problem of target shielding is greatly reduced. This means that there are in principle 
no limitations for a minimum flight path, so that large solid angles can be used which compensate for the lower source strength. With very fast pulsing systems ( $\Delta \mathrm{t} \lesssim 0.5 \mathrm{~ns}$ ), and provided that moderate neutron energy resolution is sufficient, capture cross section measurements can be carried out with the TOF technique at flight paths of a few centimeters (Mack1in, Gibbons, and Inada 1963; Wisshak and Käppeler 1978). Neutron collimation at these extremely short flight paths is achieved directly by the reaction kinematics. In $(p, n)$-reactions on ${ }^{7} \mathrm{Li}$ or ${ }^{3} \mathrm{H}$, which are used for neutron production, the proton energy is adjusted slightly above the reaction threshold so that the center-of-mass velocity of the system exceeds the velocity of the emitted neutrons. Hence a11 neutrons are kinematically collimated in a forward cone. The potential of VdG-accelerators in comparison to a modern LINAC is discussed by Käppeler (1978). If the moderate energy resolution can be accepted (and this is certainly possible for most measurements of relevance to the s-process), then VdG techniques are an effective tool for the determination of neutron cross sections. It is important to note that LINAC and VdG measurements provide data which are complementary in the sense that the respective systematic uncertainties are completely independent of each other. This allows direct judgement of the reliability of the results.

In most experiments, capture events are detected via the prompt gammacascade by which the newly formed nucleus deexcites. These so-called direct detection methods, which are supplemented by the activation technique, are discussed in a review by Chrien (1975). The basic advantage of activation measurements is their inherent sensitivity, which, however, can be fully exploited only if the following criteria are met:

- The activation samples must be placed immediately onto the neutron target to minimize scattering effects.

- Only very thin samples should be used to avoid large self-shielding effects.

- The samples should be sandwiched between gold foils or other samples which may serve as reference materials.

- The neutron flux per unit time must be recorded continuously during the activation so that corrections can be made for a non-uniform irradiation history.

- The induced activity should be counted with calibrated high resolution solid state detectors [e. g. gamma activities by Ge(Li)-counting] to minimize background effects.

- The induced activity should be counted as a function of time to verify the correct assignment of the investigated reaction. 
With a11 these precautions the method is sensitive enough to enable accurate measurements of very small cross sections and/or on very sma11 amounts of sample material. Moreover, no high sample enrichments are required, because the method is selective for specific isotopes.

The activation method, however, has two drawbacks. First, it is restricted to those isotopes for which neutron capture leads to an unstable nucleus with a half-1ife of $\lesssim 0.5 \mathrm{yr}$. Second and more serious, it provides an average cross section over the neutron spectrum which is used for activation. This problem, that the neutron spectrum has to be known accurately, has produced much confusion in the 1iterature. As a consequence, activation measurements which are reported without a simultaneous measurement of the neutron spectrum should be considered with caution.

Whereas many authors have tried to circumvent this difficulty by using "monoenergetic" neutrons, Beer and Käppeler (1980) solved the problem by tailoring a spectrum which almost perfectly imitates a Maxwellian spectrum for $\mathrm{kT}=25 \mathrm{keV}$. This was enabled by the properties of the ${ }^{7} \mathrm{Li}(\mathrm{p}, \mathrm{n})$ reaction: As was verified experimentally, integration over the emission angles of the kinematically collimated neutron beam gives a spectrum which is shown as a histogram in the lower right portion of Figure 1. Comparison with the Maxwellian spectrum for $\mathrm{kT}=25 \mathrm{keV}$ (dashed line) shows a 95\% agreement if the spectra are weighted with an $\mathrm{E}^{-1 / 2}$-dependence as is common for most cross section shapes.

Not only does activation in such a spectrum provide the proper Maxwellian average for the cross section, but also the kinematic collimation reduces neutron scattering effects near the samples to an almost negligible level. The schematic arrangement for the irradiation is given in the left part of Figure 1. Neutrons are produced in a thin $\left(1 \mathrm{mg} / \mathrm{cm}^{2}\right)$ metallic Li-layer which is evaporated onto a $0.5 \mathrm{~mm}$ thick copper backing, and the investigated sample is sandwiched between two gold foils. Because the gold cross section is accurately known and because gold can be activated as well, this material is used as a standard.

Another feature of the technique is illustrated in the upper right portion of the figure, which shows the decay curve of the ${ }^{139} \mathrm{Ba}$ activity. The fact that one observes the proper half-life for this decay ensures that all background corrections were applied correctly. With this technique the very sma11 cross sections of ${ }^{138} \mathrm{Ba}$ and ${ }^{140} \mathrm{Ce}$ were determined with an accuracy of 5 to $6 \%$. 


\section{(ii) Cross Section Compilation}

For the determination of the oN-curve one needs a complete set of Maxwellian averaged capture cross sections in the entire mass range from ${ }^{56} \mathrm{Fe}$ to ${ }^{209} \mathrm{Bi}$. We follow the usual assumption of constant temperature and compile all cross sections for a thermal energy of $30 \mathrm{keV}$ for:

$$
\sigma=\frac{\langle\sigma \mathrm{v}\rangle}{\mathrm{v}_{\mathrm{T}}}=\frac{1}{\mathrm{v}_{\mathrm{T}}} \int_{0}^{\infty} \sigma \mathrm{v} \phi(\mathrm{v}) \mathrm{dv},
$$

where $\phi(v)$ is the Maxwellian velocity distribution and $\mathrm{v}_{\mathrm{T}}=(2 \mathrm{kT} / \mathrm{m})^{1 / 2}$, $m$ being the reduced mass. In this paper a11 cross sections $\sigma$ are Maxwellian averages according to equation 1 except where we explicitely mention differential cross sections $\sigma\left(E_{n}\right)$. Our compilation is built upon the earlier evaluation of Allen, Macklin, and Gibbons (1971). We have considered new experimental values and where these are not available, recent theoretical cross section calculations.

A11 these data were condensed into what we believe is at present a best set of average cross sections. If the scatter of experimental data exceeded the quoted uncertainties, this scatter was used to determine the uncertainty of the recommended value and the various data were then only combined to a simple arithmetic mean. Otherwise, a weighted mean was calculated and the assigned uncertainty was taken in a rather realistic (that means relatively conservative) way. No attempt was made, however, to judge the reliability of different experimental results because this requires a much deeper evaluation for which most publications do not contain sufficient details.

We have always considered all experimental data even though we had some doubts in a few cases; this was necessary, however, to avoid the danger of selectively picking out those cross sections which fitted best to the calculated oN -curve. For only two exceptions did we disregard previous experimental data: the new results for ${ }^{138} \mathrm{Ba}$ and ${ }^{140} \mathrm{Ce}$ (Beer and Käppeler 1980) which are so important for the 1edge-precipice at $A=140$ were believed to be superior to existing data and were therefore adopted without modification.

Where only theoretical values exist, the uncertainties were determined by the same procedure; but even if agreement between various calculations 
was found, a minimum error of $\pm 30 \%$ is assumed for these species because theoretical calculations cannot be made with better accuracy. Presently, there are four sets of theoretically calculated cross sections by Holmes et a1. (1976), Woosley et a1. (1978), Harris (1981), and by Benzi, D'Orazi, and Reffo (1973) which are all based on the statistical mode1. While the first three sets of data were calculated with a global set of nuclear parameters such as level densities and radiative decay widths, in the fourth work, mass dependent variations of these parameters were also considered. This more localized approximation, which required extensive studies of nuclear properties, results in consistently better accuracy as can be seen from the comparison with experimental data in Tables 1 and 2 .

Because not all cross sections are equally important for $\underline{s}$-process calculations, we restrict the discussion here to the following isotopes: (i) Pure s-process nuclei: These are shielded from $\underline{r}-$ process abundance contributions by more neutron-rich stable isobars and can be used as unambiguous measures of the $\sigma \mathrm{N}_{\mathrm{s}}$-curve,

(ii) Nuclei with magic neutron numbers: These have very sma11 cross sections and hence determine the ledge-precipice structure of the $\sigma \mathrm{N}_{\mathbf{s}}$-curve.

The evaluation of all other isotopes is being summarized in an internal KfK-report. Besides the nuclei menticned above, the only relevant difference to the earlier evaluation of Allen, Macklin, and Gibbons (1971) is in the mass region below $A=64$, where we have used the experimental cross sections reported by Beer, Spencer, and Ernst (1974). Practical1y a11 other changes have a minor influence on the calculated. $\sigma \mathrm{N}$-curve.

of course, this is not true if one is going to investigate details of the $\underline{s}$-process path or if $\underline{r}$-process abundances are to be determined by subtracting $\mathrm{N}_{\mathrm{s}}$, because accurate cross sections then enter sensitively.

The collected information on the above isotopes is presented in Tables 1 and 2 . Values denoted by $(\S)$ are calculated from the differential cross section $\sigma\left(E_{n}\right)$ because no Maxwellian average was given in the respective publication. In a few cases, marked by $(||)$, data were available only in part of the energy range between 1 and $200 \mathrm{keV}$. These data were fitted by

$$
\sigma\left(\mathrm{E}_{\mathrm{n}}\right)=\mathrm{a} \cdot \mathrm{E}_{\mathrm{n}}^{-\mathrm{b}},
$$

and this expression was then used for extrapolation. 
A11 cross sections are given in millibarns (mb). Measurements previous1y considered by Allen, Macklin, and Gibbons (1971) appear in the tables only if they could be renormalized to the presently more accurately known values of the respective standard cross sections. These data are marked by (\#) in Table 1. This renormalization does not change the cross sections by more than $5 \%$.

Concluding this section, we would like to emphasize that the recommended average cross sections are determined exclusively by the nuclear properties of the respective isotopes and that at no point were astrophysical arguments allowed to influence the evaluation.

III. $\quad$-PROCESS MODEL

When the $\underline{s}$-process was first outlined by Burbidge, Burbidge, Fowler, and Hoyle (1957) there were only some indications for the characteristic correlation between cross section $s$ and abundance $\mathrm{N}_{s}$, as only very scarce information on $\sigma$ was known. The situation had improved enough four years later that Clayton et al. (1961) were able to accompany their mathematical analysis with a comparison of $\sigma \mathrm{N}_{s}$ with $\sigma \mathrm{N}_{r}$. It showed the former to be a relatively smooth and decreasing function of atomic weight, whereas the latter showed uncorrelated scatter. That contrast decisively corroborated the idea of separating heavy element nucleosynthesis into $\underline{s}^{-}$and $\underline{r}$-processes. C1ayton et a1. (1961) a1so showed that a single irradiation of iron group elements could not generate the s-process abundances but that a distribution of neutron fluences was called for, with smaller amounts of seed exposed to larger fluences. The idea of producing s-process nuclei in a single irradiation was further pursued by Amiet and Zeh (1968). However, this model failed even if the distribution of $\underline{r}-n u c l e i$ was added to the seed of iron group nuclei.

With improved techniques for cross section measurements, the $\sigma \mathrm{N}_{\mathrm{s}}$-curve could be investigated in more detail. The more recent work of Ward and Newman (1978) clearly showed two important points:

(i) Besides the main distribution of neutron irradiations, an additional weaker one has to be postulated in order to account for the rapidly increasing $\sigma \mathrm{N}_{\mathrm{s}}$-values below $\mathrm{A} \sim 90$ (and perhaps a third strong component to reproduce abundances in the lead region), and 
(ii) The sma11 cross sections of nuclei with magic neutron numbers lead to a pronounced ledge-precipice structure of the $\sigma \mathrm{N}_{\mathrm{s}}$-curve (see also Seeger, Fowler, and Clayton 1965).

Remaining problems which are predominantly due to the lack of data are quantitative knowledge of the neutron flux distribution and the seed abundances.

The s-process model which we adopt follows the one used in the work mentioned above. The abundance of an isotope A changes under s-process conditions according to

$$
\frac{\mathrm{dN}_{S}(A)}{\mathrm{dt}}=\lambda_{n}(A-1) \mathrm{N}_{S}(A-1)-\left[\lambda_{n}(A)+\lambda_{B}-(A)\right] N_{S}(A),
$$

where $\lambda_{n}=\phi \sigma$ is the neutron capture rate, which is proportional to the neutron flux $\phi$ and to the averaged cross section $\sigma$, and $\lambda_{B^{-}}=\ln 2 / T_{1 / 2}$ gives the beta-decay rate if nucleus $A$ is radioactive. Equation (3) defines a system of coupled differential equations which cannot be solved for the most general case because the coefficients $\lambda$ are time dependent through their dependence on the stellar temperature and neutron flux. For an analytic solution one therefore makes the following simp1ifying assumptions:

(i) either $\lambda_{B}>\lambda_{n}$ or $\lambda_{B}-\ll \lambda_{n}$, which means that radioactive nuclei on the synthesis path are treated as stable nuclei or are completely neglected, respectively. Consequently, in s-process branchings, estimated mean values for the respective isobars are considered instead of a complete treatment. In general, this might be justified except at the branch at ${ }^{85} \mathrm{Kr}$ where severe problems arise and are discussed later in this work.

(ii) The temperature $\mathrm{T}$ is constant during the s-process. Then one deals with well-defined cross sections and equation (3) can be rewritten, with time $t$ being replaced by the time integrated neutron flux $\tau=\int \phi \mathrm{dt}\left(\mathrm{mb}^{-1}\right)$, $\frac{\mathrm{dN}_{\mathrm{S}}(\mathrm{A})}{\mathrm{d}_{\tau}}=\sigma(\mathrm{A}-1) \mathrm{N}_{\mathrm{S}}(\mathrm{A}-1)-\sigma(\mathrm{A}) \mathrm{N}_{\mathrm{S}}(\mathrm{A})$

This system of equations can be solved analytically with an exponential distribution for the neutron fluence $\tau$ (Clayton and Ward 1974). 
For the two-component distribution

$\rho(\tau)=\frac{f_{1} N_{56}}{\tau_{01}} \exp \left(-\tau / \tau_{01}\right)+\frac{f_{2} N_{56}}{\tau_{02}} \exp \left(-\tau / \tau_{02}\right)$

one finds (see also Ulrich 1973):

$$
\begin{aligned}
\sigma(A) N_{S}(A) & =\frac{f_{1} N_{56}}{\tau_{01}} \prod_{i=56}^{A}\left[1+\frac{1}{\sigma(i) \tau_{01}}\right]^{-1} \\
& +\frac{f_{2} N_{56}}{\tau_{02}} \prod_{i=56}^{A}\left[1+\frac{1}{\sigma(i) \tau_{02}}\right]^{-1},
\end{aligned}
$$

if $\alpha$-recycling among the isotopes of lead and bismuth is neglected (Ward and Clayton 1981).

By comparison of the calculated $\sigma N$-values with the empirical values for pure s-process nuclei, one can obtain the parameters $f_{1}, f_{2}$ and $\tau_{01}, \tau_{02}$. The quantity $f$ is physically the fraction of the iron seed nuclei, $\mathrm{N}_{56}$, that have been subjected to that component of the exponential distribution of exposures. This fitting procedure is herein carried out in two steps. First, a least squares fit of the $\sigma N_{s}$-curve is performed in the mass range A > 100 where the contributions from the first, weak term in equation (6) can be neglected. Having found the parameters $\mathrm{f}_{2}$ and $\tau_{02}$, the procedure is then repeated for $A<97$ to obtain $f_{1}$ and $\tau_{01}$. A different weight inversely proportional to the uncertainty of the respective capture cross section is given to the normalization points. As no statistical uncertainties are assignable for the abundances, it was not feasible for us to consider mathematically their effect on the weighting procedure. Instead, the volatile elements like the noble gases, mercury or lead, where the abundance obviously is in question, were omitted in the fit. Because for $A<97$ there are very few pure s-process nuclei, we have included ${ }^{88} \mathrm{Sr},{ }^{89} \mathrm{Y}$ and ${ }^{90} \mathrm{Zr}$ in the calculations which are synthesized predominantly by the $\underline{s}$-process (containing less than $20 \% \underline{\text { r}}$-process contributions).

An important point for the fluence distribution is ${ }^{58} \mathrm{Fe}$. Its origin has always been a problem because its yield in the main line of thermonuclear burnings is small as reviewed by Peters, Fowler, and Clayton (1972), who discussed its production by a low-fluence s-process. In this paper we also assume that ${ }^{58} \mathrm{Fe}$ is predominantly of s-process origin. The alternatives involve neutron-rich equilibrium processes, as in the now-discarded attempt to synthesize $56,57,58$ Fe together (Burbidge et al. 1957) or 
in the attempt in even more neutron-rich matter to coproduce ${ }^{58} \mathrm{Fe}$ with ${ }^{50} \mathrm{Ti},{ }^{54} \mathrm{Cr}$ and ${ }^{62} \mathrm{Ni}$ (Truran 1972; Hainebach et al. 1974). A1though both of these processes probably produced some as yet unknown portion of ${ }^{58} \mathrm{Fe}$, we will compute the weak-fluence distribution required to produce a11 of it. A second feature of ${ }^{58} \mathrm{Fe}$ is that its cross section has historically played a large role in estimating the fluence required to produce the heavier nuclei. Its cross section has long been thought to be a smal1 $4.5 \mathrm{mb}$ (A1len, Macklin, and Gibbons 1971), but recent measurements (Hong, Beer, and Käppeler 1978; Allen and Macklin 1980) have lowered the fluence requirements by finding considerably larger values for it.

It is obvious from equation (6) that the terms $\left[1+1 / \sigma(i) \tau_{0 i}\right]^{-1}$ differ significantly from unity only for small cross sections and hence the $\sigma_{\mathrm{N}}$-curve is particularly sensitive to these values. Consequently, $\tau_{01}$ and $\tau_{02}$ are determined within rather narrow margins by the small cross sections at the magic neutron numbers. Whereas for $N=82$ there are the accurate cross sections of ${ }^{138} \mathrm{Ba}$ and ${ }^{140} \mathrm{Ce}$ to define $\tau_{02}$, the situation is more complicated near $N=50$. Because the synthesis path branches at ${ }^{85} \mathrm{Kr}$, only part of the s-process $\mathrm{flow}$ passes through the $\mathrm{N}=50$ nuclei ${ }^{86} \mathrm{Kr}$ and ${ }^{87} \mathrm{Rb}$. In the adopted treatment of s-process branches, the strong effect of the sma11 cross sections of ${ }^{86} \mathrm{Kr}$ and ${ }^{87} \mathrm{Rb}$ would be decreased significantly by averaging with their respective isobars ${ }^{86} \mathrm{Kr}$ and ${ }^{87} \mathrm{Sr}$. As the average is weighted with the branching ratio at ${ }^{85} \mathrm{Kr}$ :

$$
\mathrm{B}_{\mathbf{n}}=\lambda_{\mathrm{n}} /\left(\lambda_{\mathrm{n}}+\lambda_{\mathrm{B}}-\right)
$$

this would show up especia1ly for $B_{n} \gtrsim 0.3$. With current estimates for the effective s-process neutron density of $\sim 2 \times 10^{7} \mathrm{n} / \mathrm{cm}^{3}$ (Ward, Newman, and Clayton 1976) and with a calculated cross section of $68 \mathrm{mb}$ for ${ }^{85} \mathrm{Kr}$ (Leugers et a1. 1979), the neutron capture rate is $\lambda_{\mathrm{n}}=2 \times 10^{-2} \mathrm{yr}^{-1}$. The beta-decay rate of ${ }^{85} \mathrm{Kr}, \lambda_{B}-$, is composed of two terms, one for the decay of the short-lived isomeric state $\left(\mathrm{T}_{1 / 2}=5.5 \mathrm{~h}\right)$ for which $\lambda_{B} \rightarrow>\lambda_{\mathrm{n}}$ always holds and another one for the decay of the ground state $\left(T_{1 / 2}=10.7 \mathrm{yr}\right)$ for which $\lambda_{B}-\sim \lambda_{n}$. The probability for populating the isomeric state in ${ }^{85} \mathrm{Kr}$ (the isomeric ratio) by neutron capture in ${ }^{84} \mathrm{Kr}$ is unknown for neutron energies corresponding to s-process temperatures. However, since isomeric ratios normally 
are almost constant over a wide range in energy, the experimental value obtained with thermal neutrons will be used instead. With this assumption, $68 \%$ of all capture events on ${ }^{84} \mathrm{Kr}$ populate the isomeric state which decays to ${ }^{85} \mathrm{Rb}$ with a probability of $80 \%$. If the levels in ${ }^{85} \mathrm{Kr}$ are not thermalized as suggested by Ward (1977), then $54 \%$ of all capture events lead directly to ${ }^{85} \mathrm{Rb}$ by decay of the isomeric state and on $1 \mathrm{y} 46 \%$ yield the ground state of ${ }^{85} \mathrm{Kr}$ where neutron capture rates are comparable to the beta-decay rate. With the above estimate for $\lambda_{n}$, one finds a branching ratio of $B_{n}=0.12$. In that case averaging over the isobars would still be acceptable. However, if one assumes the much higher neutron densities derived from stellar model calculations, e.g. by Cosner, Iben, and Truran (1980), then $B_{n}$ might we11 be as high as 0.4 . Therefore, we did not rely on the procedure of averaging isobaric cross sections in the case of the branch at ${ }^{85} \mathrm{Kr}$. Instead we performed a complete calculation of the branch but still with the assumption of a steady neutron flux. The branching ratio was determined by normalizing the calculation to the empirical oN ${ }_{s}$-value of ${ }^{86} \mathrm{Sr}$. In addition to the cross sections which are included in Table 2, we have assumed in our calculations that the beta-decay rates of ${ }^{85} \mathrm{Kr}$ and ${ }^{86} \mathrm{Rb}$ do not depend on the s-process temperature (Cosner and Truran 1980) and their respective half-lives were taken from Lederer and Shirley (1978).

In addition to the parameters for the fluence distribution, another important parameter which can be derived from the s-process calculations is $n_{c}$, the average number of neutrons captured per ${ }^{56}$ Fe seed nucleus. According to clayton et al. (1961) one finds for each of the two terms of the fluence distribution in equation (5):

$$
\mathrm{n}_{\mathrm{ci}}=\frac{\sum_{A=56}^{209}(A-56) \mathrm{N}_{S}\left(\tau_{0 i}\right)}{\mathrm{f}_{i} \mathrm{~N}_{56}}=\sum_{A=56}^{209} \frac{(A-56)}{\sigma(A) \tau_{0 i}} \prod_{j=56}^{A}\left[1+\frac{1}{\sigma(j) \tau_{0 i}}\right]^{-1}
$$

for $i=1,2$, if again, the alpha-recycling among the lead and bismuth isotopes is neglected.

These quantities $\mathrm{n}_{\mathrm{c} 1}$ and $\mathrm{n}_{\mathrm{c} 2}$ are important because their values allow a comparison with the s-process neutron balance predicted by stellar model calculations. These will later be displayed in Table 4 for several different sets of assumptions. The numbers are smaller than one might naively think for making ${ }^{138} \mathrm{Ba}$, say, from ${ }^{56} \mathrm{Fe}$. This is because $\mathrm{n}_{\mathrm{C}}$ will be averaged over the range of fluences required to produce the s-process distribution, whereas only the largest fluence parts have contributed to the heaviest elements. 
IV. NEUTRON FLUENCE DISTRIBUTION

a) The $\sigma \mathrm{N}_{\mathrm{s}}$-curve

With the procedure described above, a best oN -curve was fitted to the empirical values based on the evaluated solar-system abundances of Cameron (1981) for the species which are included in Table 1.'For comparison, additional curves were also determined using the evaluations of Cameron (1973) and those of Suess and Zeh (1973) and Palme, Suess, and Zeh (1981) all of which are based on abundances of $\mathrm{Cl}$ carbonaceous meteorites.

Figure 2 shows the curve which was calculated with the abundance table of Cameron (1981). The heavy solid line corresponds to the second term in equation (6) and describes the contribution of the stronger neutron irradiation. Practically all s-process abundances of elements with A $>90$ were synthesized by this component. The weaker fluences as described by the first term in equation (6) account for the steep decrease of the $\sigma \mathrm{N}_{\mathrm{s}}$-curve from the ${ }^{56} \mathrm{Fe}$-seed, through ${ }^{58} \mathrm{Fe}$, to the nuclei with closed neutron she11s around $A=90$. The symbols of Figure 2 correspond to empirical oN $-v a l u e s$. Black squares denote pure $\underline{s}$-process nuclei with both reliable abundances and experimentally measured cross sections. Pure s-process nuclei for which the abundances are uncertain and/or for which only calculated cross sections are available, are given by open squares. The open circles represent nuclei with closed neutron she1ls which are predominantly produced by the s-process. Error bars reflect only the cross-section uncertainties as given in Tables 1 and 2 .

Overa11, excellent agreement is found between the calculated curve and the empirical values. Except for 10 points (out of 31 ), the error bars overlap with the curve which is almost exactly the statistical expectation. This is all the more satisfactory because abundance uncertainties are not yet included which themselves could we11 be $\pm 5 \%$ within certain groups of elements like the rare earths and might amount to $\pm 20 \%$ between chemically different groups. Nevertheless, there seem to be indications for some systematic discrepancies, e.g. for ${ }^{142} \mathrm{Nd},{ }^{150} \mathrm{Sm},{ }^{154} \mathrm{Gd}$, ${ }^{170} \mathrm{Yb}$ and ${ }^{186} \mathrm{Os}$. Of these, the problems with ${ }^{170} \mathrm{Yb}$ and ${ }^{186}$ os are probably due to s-process branchings at ${ }^{170} \mathrm{Tm}$ and ${ }^{185} \mathrm{~W}$ (Ward et a1. 1976; Beer et a 1 . 1980), while for ${ }^{142} \mathrm{Nd}$ there is probably a $10 \%$ abundance contribution from the p-process (see $\S \mathrm{Va}$ and Table 6). The discrepancies for ${ }^{150} \mathrm{Sm}$ and ${ }^{154} \mathrm{Gd}$ are most likely the result of uncertain capture cross sections for which experimental data are scarce or even contradictory. That the displacement of these points from the calculated $\sigma N_{s}$-curve is not due 
to the respective abundances is confirmed from the calculated abundances of Figure 5, where the other isotopes of Sm and Gd fit smoothly into the $\underline{r}$-process distribution.

The shape of the $\sigma \mathrm{N}_{\mathrm{s}}$-curve is determined to a large extent by the cross sections. While the fractional seed abundance $f$ is only a scaling factor, a change of the mean average neutron fluence $\tau_{0}$ changes the slope of the curve and the height of the steps at the magic neutron numbers. In Table 3 the resulting parameters $f$ and $\tau_{0}$ are compared for calculations based on different solar abundance tables. Although these tables differ significantly in detail, the respective differences in the parameters $f$ and $\tau_{0}$ are on1y on the order of $10 \%$. A measure of the agreement between the calculated curves and the empirical values is given by the $x^{2}$-values in the last column of Table 3 .

The two last lines in Table 3 demonstrate the important role of reliable cross section data. If the cross section evaluation of Allen, Macklin, and Gibbons (1971) is updated by the values of Tables 1 and 2 , and in the mass range $56<\mathrm{A}<64$ by the work of Beer, Spencer, and Ernst (1974), then there is practically no difference in the results for $f$ and $\tau_{0}$ which were obtained with the newly-compiled cross sections of this work. Ward and Newnan (1978) used the cross sections of Allen, Macklin, and Gibbons (1971) which were only slightly modified by the theoretical calculations of Holmes et a1. (1976). The drastic enhancement of the seed abundances which were required in their fit resulted simply because the cross sections in the region A $<70$ were clearly underestimated.

Not only the seed abundances but a1so the average number of neutrons captured per seed nucleus, $n_{c 1}$ and $n_{c 2}$, yield important information about possible s-process scenarios. The results obtained from equation are summarized in Table 4. We find that $n_{c 1}=1.1$ and $n_{c 2}=8.2$ neutron captures per exposed iron seed are required to produce the solar s-process abundances. Although the value for $\mathrm{n}_{\mathrm{c} 2}$ is twice as large as was determined by Ward, Newman, and Clayton (1976) it is still compatible with the estimates of Ulrich (1973) for a thermally pulsing $7-M_{\Theta}$ star (see $\$$ VII).

The numerical results which were obtained in the fit of the $\sigma \mathrm{N}_{\mathrm{s}}$-curve using the abundance table of Cameron (1981) are 1isted in Table 7 together with the resulting $\underline{r}$-process residuals. 
b) The s-process branch at ${ }^{85} \mathrm{Kr}$

The fact that the half-life of ${ }^{85} \mathrm{Kr}$ does not change at temperatures of typical s-process environments (Cosner and Truran 1980), makes the branching at ${ }^{85} \mathrm{Kr}$ well-suited for an estimate of the s-process neutron

flux. Figure 3 shows the s-process flow through the mass region $84<\mathrm{A}<92$. Branching points are shaded and pure s-process isotopes are marked by double boxes. For the magic nuclei with $\mathrm{N}=50$ one finds from the smoothness of $\underline{r}$-process abundances that this component can be neglected; the respective isotopes are indicated by dashed inner boxes.

The branching ratio $B_{n}$ can now be calculated in two ways, either by comparing the $\sigma N_{s}$-values of ${ }^{84} \mathrm{Kr}$ and ${ }^{86} \mathrm{Kr}$ or those of ${ }^{86} \mathrm{Sr}$ and ${ }^{88} \mathrm{Sr}$. With our $\sigma_{\mathrm{s}}$-curve of Figure 2 we find for the first case a branching ratio of $B_{n}=0.18$ corresponding to a neutron density of $n_{n}=5.9 \times 10^{7} \mathrm{~cm}^{-3}$. Due to this small neutron density, there would be no additional branching at ${ }^{86} \mathrm{Rb}$ and consequently the strontium isotopes would be overproduced by about a factor of two. This problem would even be enhanced, if a correction is applied for a possible $\underline{r}$-process contribution to the ${ }^{86} \mathrm{Kr}$-abundance.

Therefore, the determination of $\mathrm{B}_{\mathrm{n}}$ via ${ }^{86} \mathrm{Sr}$ is certainly more reliable. In principle, one can try to deduce the branching ratios from a comparison of the $\sigma \mathrm{N}_{\mathrm{s}}$-values of ${ }^{86} \mathrm{Sr}$ and ${ }^{88} \mathrm{Sr}$. However, in view of the cross section uncertainty of ${ }^{88} \mathrm{Sr}(16 \%)$, we preferred instead to start from the calculated $\sigma \mathrm{N}_{\mathrm{s}}$-curve of Figure 2. The branching ratios were chosen such that the s-process flow through ${ }^{86} \mathrm{Sr}$ reproduces the empirical $\sigma \mathrm{N}_{\mathrm{s}}$-value of this isotope. Figure 3 describes the particular situation which was obtained for the abundance table of Cameron (1981). The second shielded s-isotope in the branch, ${ }^{87} \mathrm{Sr}$, was not used for normalization because it is unclear how the decay of ${ }^{87} \mathrm{Rb}$ and a possible reverse electron-capture decay from ${ }^{87} \mathrm{Sr}$ at high temperatures might influence its abundance. In the following, we modified the quoted solar abundances of ${ }^{87} \mathrm{Sr}$ and ${ }^{87} \mathrm{Rb}$ as if ${ }^{87} \mathrm{Rb}$ has decayed with its terrestrial half-life since it was produced about 6 billion years before the formation of the solar system (Clayton 1964). This means that the ${ }^{87} \mathrm{Rb}$-abundance of Cameron (1981) was increased by $8 \%$ leading to a corresponding reduction of the ${ }^{87} \mathrm{Sr}$ abundance by $\sim 10 \%$. 
As a consequence of normalizing the calculation to ${ }^{86} \mathrm{Sr}$, we find for ${ }^{85} \mathrm{Kr}$ an effective branching ratio $B_{n}=0.43$. The assumption that the isomeric ratio into ${ }^{85} \mathrm{Kr}$ measured with thermal neutrons on ${ }^{84} \mathrm{Kr}$ still holds in the range of stellar energies immediately defines an upper 1 imit $B_{n}^{\max }=0.46$ for this s-process branching ratio. Our observed value for $B_{n}$ being so close to this upper limit implies a neutron capture rate by the ground state of ${ }^{85} \mathrm{Kr}$ which is about 15 times larger than the beta decay rate and in turn this yields a rather high neutron density of $n_{n}=2 \times 10^{9} \mathrm{~cm}^{-3}$.

It is obvious now that with such a high neutron density the simplified assumption $\lambda_{\beta} \rightarrow>\lambda_{\mathrm{n}}$ no longer holds for many more nuclei such as ${ }^{86} \mathrm{Rb}$, ${ }^{89} \mathrm{Sr}$, or ${ }^{90} \mathrm{Sr}$, so that these isotopes also act as s-process branching points. The respective branching ratios are given in the tabular insert of Figure 3. The 1 ines between the various isotopes mark the s-process synthesis path and the related numbers represent the percentage of the total flow of neutron-capture current.

Figure 4 corresponds to the framed region of Figure 2 that illustrates in detail how the $\sigma \mathrm{N}_{\mathrm{s}}$-curve splits up into the various branches. The part containing ${ }^{86} \mathrm{Kr}$ is shown as a dotted line whereas the fraction which proceeds through ${ }^{85} \mathrm{Rb}$ and splits at ${ }^{86} \mathrm{Rb}$ is dashed. For clarity, all components are given separately until ${ }^{88} \mathrm{Sr}$. In this figure, the minor branchings at ${ }^{89} \mathrm{Sr}$ and ${ }^{90} \mathrm{Sr}$ are neglected because they cannot be treated properly due to the lack of cross sections. However, their impact on the $\mathrm{ON}_{\mathrm{s}}$-curve is very smal1 in any case.

Between $A=84$ and 88 , the overall $\sigma N_{s}$-curve in Figure 4 falls by $70 \%$ and meets the empirical value for ${ }^{88} \mathrm{Sr}$ within its uncertainty. This is a significant improvement over the simplified treatment of s-process branches, because then the effect of the sma11 ${ }^{86} \mathrm{Kr}$ cross section is lost when it is averaged with the larger one of ${ }^{86} \mathrm{Sr}$. In that case, the corresponding decrease of $\sigma \mathrm{N}_{\mathrm{s}}$ would be $22 \%$ smaller and therefore the calculated $\underline{s}$-process overproduction would be more severe and extends up to $92 \mathrm{Zr}$.

For all pure $\underline{s}$-nuclei and also for those nuclei where $\underline{r}$-process contributions are negligible, the empirical $\sigma \mathrm{N}_{\mathrm{s}}$-values are shown for comparison. Since Figure 4 holds for the actual duration of the s-process, the solar abundances of Cameron (1981) are corrected for the later decay of unstable 
isobars ( $8 \%$ for both ${ }^{86} \mathrm{Sr}$ and ${ }^{87} \mathrm{Sr}$ ). A11 these points - with the exception of ${ }^{86} \mathrm{Kr}$ - are in fair agreement with the calculated curves, although there is certain1y some overproduction in the region $87<\mathrm{A}<89$. But for ${ }^{86} \mathrm{Kr}$ and for ${ }^{87} \mathrm{Rb}$, a severe overproduction is obtained from our calculation $\left(\mathrm{N}_{\mathrm{S}}^{\mathrm{calc}} / \mathrm{N}_{\mathrm{O}}=2.4\right.$ and 3.2 , respectively).

Of course, these results for the ${ }^{85} \mathrm{Kr}$ branching depend not only on the nuclear properties of the isotopes involved but also on the adopted abundances. Therefore, the ${ }^{85} \mathrm{Kr}$ branching was further analyzed using the other abundance tables quoted in Table 3. The resulting branching ratios, neutron densities and overproduction factors are summarized in Table 5. As a first result, we find that the branching ratios for ${ }^{85} \mathrm{Kr}$ are nearly equal but that the respective neutron densities are sensitively dependent on these values. This is simply due to the fact that most of the beta decays to ${ }^{85} \mathrm{Rb}$ occur from the isomeric state in ${ }^{85} \mathrm{Kr}$. In other words, while the branching ratio at ${ }^{86} \mathrm{Rb}$ follows closely the s-process neutron density, the one at ${ }^{85} \mathrm{Kr}$ is in first approximation determined by the isomeric ratio. This makes it difficult to deduce a reliable value for the neutron density. The results of Table 5 suggest an uncertainty of $\sim 50 \%$, but this refers only to the influence of the $\sigma \mathrm{N}_{\mathrm{s}}$-curves based on different solar abundance evaluations. If one also considers the uncertainties in the neutron capture cross section of ${ }^{85} \mathrm{Kr}( \pm 50 \%)$, in the beta decay rate (which is calculated by Cosner and Truran (1980) to be constant with temperature up to $\mathrm{T}_{8}=3$ ), and in the isomeric ratio (which is the value measured with thermal neutrons), then it turns out that the isomeric ratio causes the largest uncertainty. Especially if this ratio is increased, this has a dramatic effect because then the upper 1 imit for $B_{n}$ quickly approaches the observed value. For instance, a $2 \%$ increase in the isomeric branching ratio forces a factor of four increase in neutron density. This calls for a very accurate measurement of the isomeric ratio at neutron energies around $30 \mathrm{keV}$. At present, therefore the analysis of the ${ }^{85} \mathrm{Kr}$ branching only yields an estimate of $\sim 2 \times 10^{9} \mathrm{~cm}^{-3}$ for the s-process neutron density (see also $\S$ VIII).

Another problem with the ${ }^{85} \mathrm{Kr}$-branching is outlined in the 1 ast two columns of Table 5. It was impossible with our data base and our s-process mode1 to avoid the overproduction of ${ }^{86} \mathrm{Kr}$ and ${ }^{87} \mathrm{Rb}$ even if we neglect the comparably small $\underline{r}$-process contributions. But as long as the available 
information on the nuclear parameters relevant to this branching is not significantly, improved, the overproduction problem of ${ }^{86} \mathrm{Kr}$ and ${ }^{87} \mathrm{Rb}$ remains unsolved. It should be noted, however, that our overproduction factors are much smaller than those obtained by Cosner, Iben, and Truran (1980) who demonstrated the effect of a time varying neutron flux. Unfortunately, no direct comparison can be made because these authors used somewhat different cross sections.

\section{V. r-PROCESS RESIDUALS}

a) p-process contributions

In our decomposition of solar abundances into $\mathrm{N}_{\mathrm{s}}$ and $\mathrm{N}_{\mathrm{r}}$, we have not subtracted $\underline{p}$-process contributions. One reason for this is practicality. The $\underline{p}$-process theory today is not good enough to make this correction with confidence, so that we prefer to make no correction. This approach is easier to interpret than one based on some assumed smooth curve of p-process abundances.

The second reason for excluding p-corrections is that we judge them likely to be small for $\underline{\mathbf{s}}-$ only nuclei, and even smaller for the $\underline{\mathbf{r}}$-abundances.

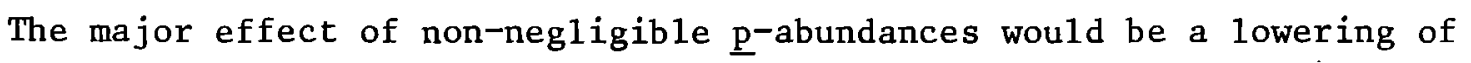
the $\sigma \mathrm{N}_{\mathrm{s}}$-curve by lowering the percentage of shielded (s-only) isotopes actually resulting from the s-process. It is not hard to see that this is a potentially important problem; for example, the abundance of $\underline{p}$-process ${ }^{144} \mathrm{Sm}$ is $41 \%$ of the abundance of $\underline{s}^{-o n} 1 \mathrm{y}{ }^{150} \mathrm{Sm}$. We therefore digress into a study that leads us to the conclusion that $\underline{p}$-corrections are not of great significance.

The major uncertainty is the nature of the process itself. For both astrophysical and nuclear reasons we think that the photodisintegration flow, for which Woosley and Howard (1978) provided a recent and quantitative analysis, is preferable to rapid captures of protons, as envisioned by Burbidge et al. (1957) and recently calculated by Audouze and Truran (1975). The former mechanism is best called "the gamma-process" or $\underline{p}$ (hotodisintegration) process as Woosley and Howard suggest, but for genera1 discussions we still speak of "p-process nuclei, abundances, and yields", using gamma-process only when we wish to distinguish this special form of $\underline{p}$-process. One of the strongest arguments (Clayton 1978; Ward and Beer 1981) in favor of the gamma-process is the low yield at odd-A ${ }^{115} \mathrm{Sn}$ allowed to p-process nucleo- 
synthesis because its abundance can be almost totally accounted for by smal1 branchings in the $\underline{s}^{-}$and $\underline{r}-$ processes. Woosley and Howard (1978) showed that ${ }^{115} \mathrm{Sn}$ production is indeed negligible in the gammaprocess, whereas Audouze and Truran (1975) found it to be substantial in the proton-capture process. This argument, as well as others based on separation energies (Mack1in 1970), seems to us strong enough to favor the gamma-process.

We have studied complete computer printouts of the gamma-process that were generously provided to us by Woosley and Howard. A general feature of this stripdown of $\underline{s}^{-}$and $\underline{r}$-nuclei is the following: by the time large overabundances of the $\underline{p}^{-i s o t o p e s}$ in element $Z$ have been established, the heavier issotopes of that element have been almost entirely eroded by the $(\gamma, n)$ destruction. This means that the overabundances of $\underline{s}-o n 1 y$ isotopes are much smaller than those of the $\underline{p}$-isotopes whenever those of the latter are large. We illustrate this in Table 6 by reproducing, with their permission, results of Woosley and Howard's elaborate calculation that were not included in their published paper. The final overabundances [defined as the ratio $\mathrm{N}$ (zone)/N $\mathrm{N}_{\odot}$ ] within zones of six different peak temperatures are listed for both

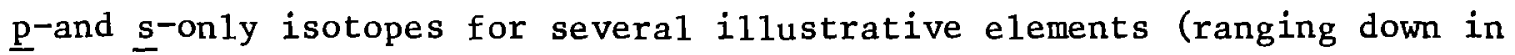
atomic weight from $\mathrm{Hg}$ to $\mathrm{Mo}$ ). The column $<0>$ represents the average overabundances resulting from equal masses ejected from each of the six zones. For clarity, consider the dysprosium isotopes. The average overabundance $\langle 0\rangle=200$ for the $\underline{p}^{-i s o t o p e}{ }^{158}$ Dy means that if $1 / 200$ of all heavy elements were ejected in such zones, the natural abundance of ${ }^{158}$ Dy would be accounted for. By comparison, the same result would account for $175 \%$ of the ${ }^{156}$ Dy abundance but on $1 y$ $7 \%$ of the s-only ${ }^{160}$ Dy abundance. The first two isotopic yields were given in Table 4 of Woosley and Howard, whereas we have added the $\underline{s}$-isotope yields from their printouts. In the $\mathrm{N}_{\mathrm{p}}$ colum we 1 ist the abundances (Cameron 1981) of the $\underline{p}$-isotopes and, in parentheses, the abundance of the $\underline{s}$-isotope resulting from comparison of its overabundance (20 for ${ }^{160} \mathrm{Dy}$ ) with an average for $\underline{p}^{-n u c l e i}$ in that region $[(350+200) / 2$ for Dy]. These absolute $\underline{p}$-yields are often 1arger than those of the $\underline{p}^{-i s o t o p e s, ~ a l t h o u g h ~ t h e ~}$ percentage of the $\underline{s}$-isotopes produced is smaller. The estimated $\underline{p}-y i e 1 d$ of ${ }^{142} \mathrm{Nd}$, for example, is three times larger than the p-peak (Cameron 1981) at ${ }^{144} \mathrm{Sm}$, although that large yield N ${ }_{\mathrm{p}}\left({ }^{142} \mathrm{Nd}\right)=0.02$ is only $10 \%$ of the total ${ }^{142} \mathrm{Nd}$ abundance (which is therefore $90 \%$ s-process in origin). Another example of interest shows that $4.8 /[(48+94) / 2]=6.8 \%$ of ${ }^{130} \mathrm{Xe}$ is due to this particular gamma-process calculation if the two $\mathrm{p}$-isotopes are produced rough1y correct1y. This influences the CCF Xenon fission spectrum in the way 
shown by C1ayton (1976) for a different $\underline{p}$-process model. The $\underline{p}$-contribution to s-only ${ }^{128}$ Xe is still larger. For Sn one sees a $3 \%$ production of ${ }^{116} \mathrm{Sn}$ if the average for ${ }^{112} \mathrm{Sn}$ and ${ }^{114} \mathrm{Sn}$ are correct, and, at the same time, the low ${ }^{115}$ Sn yields that are so important to the diagnostic argument made above. only in the low range of atomic weights (e.g. Mo) do the s-only overabundances become significant fractions of the $\underline{p}$-overabundances; but then the $\underline{p}$-overabundances themselves are no longer large. Woosley and Howard (1978) called attention to this problems at the lower range of $\mathrm{A}$, calling for an enhanced nonsolar seed distribution.

Although this gamma-process model may not be tota1ly realistic, and may not have the correct superposition of peak temperatures and seed abundances, we think that these results justify neglecting the $\underline{p}$-contributions to $\underline{s}^{-o n} 1 \mathrm{y}$ nuclei as being $\leqq 10 \%$. We can only admit that this is an aspect of the $\sigma N_{s}-$ correlation that needs improving as the quantitative results of p-process calculations ałso improve.

\section{b) r-process abundances}

Besides the $\underline{s}-$ and $\underline{p}$-process, the $\underline{r}$-process contributes a large fraction to the observed solar system abundances. By neglecting the p-process yield, the difference between solar abundances $\mathrm{N}_{\odot}$ and $\underline{\text { s-process abundances (as }}$ derived from the calculated $\sigma \mathrm{N}_{\mathrm{s}}$-curve of $\mathrm{Fig}$. 2) yields a good approximation to the $\underline{r}$-process abundance contributions $\mathrm{N}_{\mathbf{r}}$. In case of $\underline{s}$-process branchings, $\underline{r}-$ process abundances are quoted only if the respective s-process contributions are less than $20 \%$ because then our averaged treatment of branchings can be tolerated. Consequently, no values for $\mathrm{N}_{\mathrm{r}}$ are given for ${ }^{63} \mathrm{Cu},{ }^{64} \mathrm{Ni},{ }^{79} \mathrm{Br},{ }^{80} \mathrm{Se}$, and ${ }^{81} \mathrm{Br}$. The problems with the ${ }^{85} \mathrm{Kr}$-branching were already discussed; here only for ${ }^{85} \mathrm{Rb}$ can a reasonable $\underline{\underline{r}}$-process abundance be given.

The difference $\mathrm{N}_{0}-\mathrm{N}_{\mathrm{S}}$ is shown in Figure 5 and numerical values are listed in Table 7. It was mentioned in $\$$ III that cross section uncertainties were unimportant for the determination of the $\sigma \mathrm{N}_{\mathrm{s}}$-curve (except for normalization points and for cross sections smaller than $\sim 100 \mathrm{mb}$ ). However, at this point, in deriving $\mathrm{N}_{\mathrm{s}}$ from the calculated $\sigma \mathrm{N}_{\mathrm{s}}$-curve, the cross section uncertainties propagate directly and are therefore particularly important where the s-process contributions dominate the observed solar abundances. Therefore, the " $\mathrm{N}_{\mathbf{r}}$ "-distribution of Figure 5 is plotted by different symbols according 
to the relative $\underline{\mathrm{r}}$-process contributions. Points for which $\mathrm{N}_{\mathrm{r}} / \mathrm{N}_{\mathrm{e}}<0.3$ are most affected by cross section uncertainties and are therefore less significant.

In general, the distribution of Figure 5 exhibits the smoothness characteristic of the $\underline{r}$-process abundances with pronounced maxima around $A=130$ and $A=195$. There is also good agreement between the calculated " $N_{r}$ " distribution (open symbols) and the solar abundances of pure $\underline{r}$-nuclei (black squares). This observation confirms that most $\underline{s}$-process abundances were accounted for properly.

In the following, we discuss the problems which still remain in our analysis and which may be due to insufficiently known cross sections and/or to uncertain solar abundances. Of course, we also must keep in mind that there might be discrepancies which are unresolved because of our simple s-process mode1.

- The mass region $56<\mathrm{A} \lesssim 70$ is dominated by abundance contributions created in the e-process and is discussed separately in $\S \mathrm{VI}$.

- Between $70<\mathrm{A}<90$, the distribution in Figure 5 shows a pronounced odd-even effect which is considerably larger than in any other part of the figure. This group of nuclei may represent a third maximum in the " ${ }_{r}$ "-distribution corresponding to the closed neutron shel1 at $\mathrm{N}=50$.

- In the regions where s-process abundances are equal to or greater than the contributions from the $\underline{r}$-process, one finds a rather large scatter of data points around the expected smooth distribution, which can be understood in most cases from the respective cross section uncertainties. For instance, ${ }^{91} \mathrm{Zr},{ }^{97} \mathrm{Mo},{ }^{120} \mathrm{Sn}$, or ${ }^{137} \mathrm{Ba}$ belong to this category. A11 of the elements containing them have severa1 isotopes which a11 fit into a smooth distribution so that the elemental abundances are probably correct. For ${ }^{91} \mathrm{Zr},{ }^{120} \mathrm{Sn}$, and ${ }^{137} \mathrm{Ba}$ a change of $\sim 25 \%$ in the cross sections would be sufficient to resolve the discrepancy, but for ${ }^{97}$ Mo a much higher value of $1400 \mathrm{mb}$ would be required as compared to the compiled cross section of $350 \pm 50 \mathrm{mb}$ (Allen, Macklin, and Gibbons 1971) which is confirmed by a more recent evaluation (Fort, Thuong, and Lafond 1977). In this 1 atter case, a reduction of the Mo abundance as measured by Palme et al. (1981) would only aggravate the discrepancy for ${ }^{97} \mathrm{Mn}$. 
The situation for ${ }^{139} \mathrm{La}$ and ${ }^{140} \mathrm{Ce}$ is much less critical because

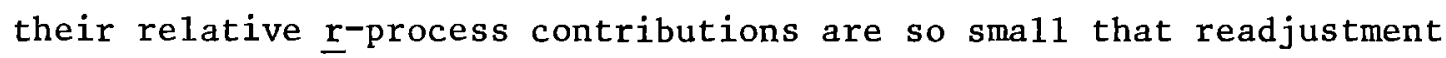
of the cross sections within the quoted uncertainties would be quite sufficient to remove the deviations from a smooth distribution. However, ${ }^{133} \mathrm{Cs}$ can be brought into better agreement with a smooth " $\mathrm{N}_{\mathrm{r}}$ "-distribution only if its abundance is raised by approximately a factor of two. Whether this is reasonable cannot be decided from the general abundance pattern because ${ }^{133} \mathrm{Cs}$ is a monotope.

Besides these local problems there is a more general one concerning the shape of the $N_{r}$ peak around $A=130$, because its height is strongly determined by the elemental abundances of $\mathrm{Te}$ and Xe. For Xe no reliable solar abundance can be determined experimentally and therefore the value quoted by Cameron (1981) was estimated from an interpolation between neighboring elements. This estimate is further complicated because the immediate neighbors are the monotopic elements Cs and I. Also, the abundance for $\mathrm{Te}$ has a considerable uncertainty. However, because

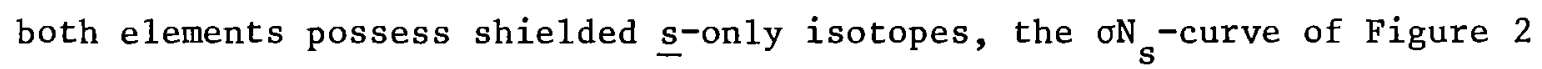
can be used to comment on these questions. One finds that according to Figure 2 the Te abundance seems to be too high by about $30 \%$ whereas the Xe-points are not significant enough for a comnent. A $30 \%$ reduction in the Te abundance would agree well with a recent measurement of Palme (1981) who found a 25\% smaller value than Cameron (1981). In Figure 5, the two r-only isotopes of Te would then fit very well with

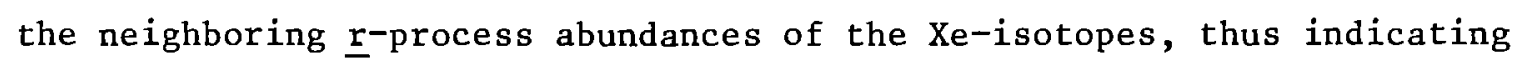
that the estimated Xe-abundance is probably correct.

Another distortion of the smooth " ${ }_{r}$ "-distribution is observed for $\mathrm{Hf}$ and $\mathrm{W}$ around $\mathrm{A}=180$. Again, this could be due to the solar abundance values of Cameron (1981). The discrepancies can be avoided by a slight decrease of the hafnium abundance if the tungsten abundance is also reduced to the value of $N_{\odot}(W)=0.13$ reported by Wänke et al. (1974), as is demonstrated by Beer, Käppeler, and Wisshak (1981). The most severe problem arise for those isotopes where the calculated $s$-process abundances exceed the solar values. Apart from ${ }^{86} \mathrm{Kr}$ and $\overline{8}_{\mathrm{Rb}}$ (see $\S \mathrm{IVb}$ ), this also occurs for the mercury isotopes $200,201,202 \mathrm{Hg}$. In view of its volatility, it is not surprising that the abundance of mercury was found to fluctuate strongly in meteorite analyses. For that reason, the abundance quoted by Cameron (1981) represents an adjustment according to nucleosynthesic criteria. If we would adjust the Hg-abundance 
to our $\sigma \mathrm{N}_{\mathrm{s}}$-curve by means of the shie1ded $\underline{s}^{-o n 1 y}$ isotope ${ }^{198} \mathrm{Hg}$, we would find an even lower value. This contradiction clearly shows that at least the capture cross section of ${ }^{198} \mathrm{Hg}$ must be wrong. Up to now there are no capture cross section measurements on mercury available and therefore this problem is left open.

At this point we should note an additional interesting effect that is clearly shown in Table 7. From the entry given there for doubly-magic, s-only ${ }^{208} \mathrm{~Pb}$ we see that only $27 \%$ of its observed solar-system abundance can be accounted for by the two-component form for $p(\tau)$ given in equation (5). This underproduction coupled with the likelihood that

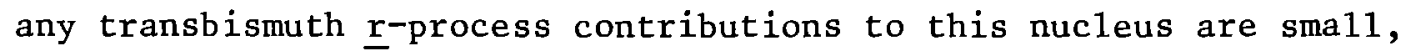
prompted Clayton and Rassbach (1967) to propose an additional component in $\rho(\tau)$. The upshot of their considerations (and confirmed in a more detailed re-examination by Ward and clayton [1981]) is that this additional component must have a sufficiently large neutron fluence of $\imath^{2} \mathrm{mb}^{-1}$ (corresponding to $\imath^{90}$ neutron captures per iron seed) to drive a very small fraction of seed nuclei to a near-equilibrium recycling distribution among $206,207,208 \mathrm{~Pb}$ and ${ }^{209} \mathrm{Bi}$. Such a distribution then naturally favors the production of additional quantities of ${ }^{208} \mathrm{~Pb}$ because of its very small cross section.

VI. THE MASS REGION A $<70$

a) The iron peak

Because of their large binding energies, most isotopes in the iron peak are formed in fusion reactions during explosive nuclear burning and their abundances are not greatly influenced by the $\underline{s}$-process. However, there are two important exceptions: ${ }^{54} \mathrm{Cr}$ and ${ }^{58} \mathrm{Fe}$ do not result from reactions with charged particles or from the standard e-process calculations because of their unusually large neutron excesses. As $\underline{r}$-process contributions are important only for $\mathrm{A} \gtrsim 70$, it was assumed that ${ }^{58} \mathrm{Fe}$ could be used as a normalization point for the $\sigma \mathrm{N}_{\mathrm{s}}$-curve. If our neutron fluence distribution $\rho(\tau)$ in equation (5) is applied for the lighter elements in the iron peak, $\mathrm{Cr}$ and $\mathrm{Mn}$, the only important seed nuclei are ${ }^{52} \mathrm{Cr}$ and ${ }^{55} \mathrm{Mn}$. We have therefore considered the respective fractions $f_{i}$ of these solar abundances as seed to determine the s-process contributions $\mathrm{N}_{\mathrm{s}}$. In Figure 6 , the abundances $\mathrm{N}_{\mathrm{e}}$ from explosive nuclear burning (values are from 
Figure 24 in Woosley, Arnett, and Clayton [1973] for a neutron excess of $1.53 \times 10^{-3}$ ) and the s-process contributions $\mathrm{N}_{\mathrm{s}}$ derived in our calculations are compared to the solar abundances $N_{\odot}$ from Cameron (1981) which are expected to represent approximately the sum of these two components. One finds that the solar values are well reproduced for A > 56 but that on an average the calculated abundances of the lighter isotopes are deficient by up to a factor of four. The largest discrepancy occurs for ${ }^{54} \mathrm{Cr}$ and the problem cannot be removed even if the capture cross section of ${ }^{54} \mathrm{Cr}$ is decreased by an order of magnitude. One possibility to explain the calculated deficiencies of ${ }^{53,54} \mathrm{Cr}$ and ${ }^{55} \mathrm{Mn}$ might be that they are in fact produced by spallation reactions on their more abundant neighbors.

In general, it is interesting to note that s-process abundances (which are normalized to ${ }^{58} \mathrm{Fe}$ ) are significant in those cases where the contributions from nuclear burning are sma11 or even negligible compared to the solar values, e.g. for ${ }^{54} \mathrm{Cr},{ }^{59} \mathrm{Co}$, and ${ }^{63} \mathrm{Ni}$.

b) $22<\mathrm{A}<56$

The abundances of nuclei lighter than ${ }^{56} \mathrm{Fe}$ are significantly influenced by nuclear structure effects because they were synthesized mostly by alpha capture reactions during oxygen and silicon burning resulting in large fluctuations of isotopic and elemental abundances. This irregular abundance pattern can be used as a sensitive test of the $\underline{s}$-process neutron fluence distribution which was determined by fitting the heavy element abundances. When an abundant isotope is followed by a rare one, the first can a1ways be considered as a seed for producing its neighbor via neutron capture. In this section we demonstrate that there is no overproduction of rare isotopes even for the most critical examples. Although more than $80 \%$ of the production of these nuclei is accounted for by the first term of equation (6), a11 calculations were carried out with the complete fluence distribution. Solar abundances are those of Cameron (1981) and the same fractions $f_{1}$ and $f_{2}$ of these solar abundances were used as seed, just as for ${ }^{56} \mathrm{Fe}$.

Most of this discussion concentrations on the $\mathrm{Ar}-\mathrm{K}-\mathrm{Ca}$ region. The seed nuclei are ${ }^{36,38} \mathrm{Ar}$ and ${ }^{40,42} \mathrm{Ca}$. For the nuclei ${ }^{39} \mathrm{Ar},{ }^{40} \mathrm{~K}$, and ${ }^{41} \mathrm{Ca}$, the factors $\left(1+1 / \tau_{0} \sigma\right)^{-1}$ are calculated not from $\sigma(n, \gamma)$ but from $\sigma=\sigma(n, \gamma)+\sigma(n, \alpha)$, and subsequent $\sigma N_{s}$-values derived from the radiative 
capture must be multiplied by the radiative capture branching ratio: $\mathrm{f}_{\mathrm{n}, \gamma}=\sigma(\mathrm{n}, \gamma) /[\sigma(\mathrm{n}, \gamma)+\sigma(\mathrm{n}, \alpha)]$. In Table 8 a11 relevant information is summarized, including the cross sections and the values of $f_{n, \gamma^{*}}$ Results are shown for four different chains $\sigma_{N}{ }_{s}^{(i)}$ to demonstrate their relative importance: $\sigma N_{s}{ }^{(1)}$ represents Ca yields from that branch of ${ }^{40} \mathrm{Ca}$ seed nuclei passing radiatively through ${ }^{41} \mathrm{Ca}$ (which is stable on the time scale of the s-process); $\sigma \mathbf{N}_{s}{ }^{(2)}$ is the specific yield from the ${ }^{42} \mathrm{Ca}$ seed nuclei. The first term clearly dominates Ca production by the s-process and we show it explicitly to illustrate that ${ }^{44} \mathrm{Ca}$ cannot be produced in this way as was suggested by Cameron (1979). This is an important statement for gamma-ray astronomy (Clayton 1981) because it supports the idea that ${ }^{44} \mathrm{Ca}$ is the decay product of ${ }^{44} \mathrm{Ti}$ which is produced in explosive events like supernovae by a rapid $(\alpha, \gamma)$ chain.

The path $\sigma \mathrm{N}$ (3) tabulates yields including the ${ }^{36,38} \mathrm{Ar}$ seed under the assumption that ${ }^{37} \mathrm{Ar}$ and ${ }^{39} \mathrm{Ar}\left(\mathrm{T}_{1 / 2}=269 \mathrm{yr}\right)$ decay in the chain. The entry $\mathrm{oN}_{\mathrm{S}}{ }^{(4)}$ replaces $\mathrm{oN}_{\mathrm{S}}{ }^{(3)}$ if ${ }^{39} \mathrm{Ar}$ is stable during the s-process which seems to be more plausible because the first excited state in ${ }^{39} \mathrm{Ar}$ is at $1.267 \mathrm{MeV}$ so that any thermally-enhanced beta-decay due to this state is unlikely. Therefore $\sigma_{\mathrm{N}}{ }_{\mathrm{S}}^{(4)}$ was used to calculate the values $\mathrm{N}_{\mathrm{s}}$ tabulated in column 7. Comparison with $\mathrm{N}_{\odot}$ from Cameron (1981) shows that this s-process fails by a large margin to account for $42,43,44 \mathrm{Ca}$. The inadequacy is especially severe at ${ }^{44} \mathrm{Ca}$, which is the isotopic yield of such significance for gamma-ray astronomy.

The nuclei ${ }^{32,33} \mathrm{~S}$ should be considered in this context as another isotopic pair because there exist experimentally determined cross sections for the $(n, \gamma)$ reactions and for the $(n, \alpha)$ reaction on ${ }^{33} S$ as well (Auchampaugh et al. 1975). Again, as in the Ar-K-Ca-region, we find that the abundance contributions from the s-process are much smaller than the respective solar values. If we also include ${ }^{34} \mathrm{~S}$ and ${ }^{35} \mathrm{C} 1$ using the theoretical cross sections of Woosley et al. (1978), the following s-process contributions are obtained: $\mathrm{N}_{\mathrm{s}}\left({ }^{33} \mathrm{~S}\right)=1.3 \%$ of $\mathrm{N}_{\odot}, \mathrm{N}_{\mathrm{s}}\left({ }^{34} \mathrm{~S}\right)=2.6 \%$ and $\mathrm{N}_{\mathrm{S}}\left({ }^{35} \mathrm{C} 1\right)=2.3 \%$.

These calculations show that the s-process neutron fluence determined for $\mathrm{A}>56$ does not lead to any overproduction of isotopes below the iron group but that instead the s-process synthesis is almost negligible in this mass range. 
VII. COMPARISON TO A STELLAR MODEL

Figures 2 and 5 are constructed with the traditional idea of a steady neutron flux; the s-process branching then is analyzed with constant branching conditions. It has been argued in recent years that He-burning shell flashes in double-shelled stars offer the most plausible astrophysical site for the s-process (Truran and Iben 1977). Despain (1980) argued against this because the average neutron flux in the bursts seemed to be too great to allow certain beta decays (especially at ${ }^{85} \mathrm{Kr}$ ) to have their needed effect. Cosner, Iben, and Truran (1980) have countered that although the flow does move into $\underline{r}$-isotopes during the peak of the pulse, the beta decays compete sufficiently during the decline of the free-neut-ron density to restore the capture path to approximately the traditional one.

A consequence of this model is, however, that a portion of the $\underline{r}-$ abundances shown in Figure 5 are actually produced by the intense neutron burst and partially survive the decay of that flux. This means that the actual s-process may produce a varying fraction of some of the isotopes separated out in Figure 5 as "r as the difference between the total abundance and an idealized, steady $\underline{s}^{-}$ process rather than the actual process. Even so, the basic features of the $\mathrm{r}$-abundances will remain real, because the pulsed s-process cannot produce the $\underline{r}$-process peaks. A separate $\underline{r}$-process resembling that in Figure 5 is still needed.

The fluence distribution $\rho(\tau)$ is virtually independent of these considerations, however, because the flow still passes overwhelmingly through the same small cross sections at neutron-magic nuclei that dominate the calculated curves of Figure 2. Moreover, the total number of nuclei synthesized, which must equal the integral of $\rho(\tau)$, is not great1y different in the pulsed s-process. The $\rho(\tau)$ extracted in Figure 2 can thus be taken as a general astrophysical requirement for the s-process, whether steady or pulsed.

Cosner, Iben, and Truran (1980) have pointed out that the pulsed $\underline{s}$-process flux causes a characteristic abundance pattern at the s-process branchings. This comes about because the abundances within a branch freeze-out as soon as the neutron density in the pulse has fallen below that limit where even the isotope with the largest cross section cannot likely capture further neutrons. This limit is given by $\sigma \tau \lesssim 1$ with $\tau(t)$. 
being the neutron exposure from time $t$ to the end of the pulse. The neutron exposure $\tau$ is related to the neutron density for which Cosner, Iben, and Truran (1980) calculated the time dependence shown in Figure 7.

According to this model, one should expect that the neutron densities obtained from various $\underline{s}$-process branchings with the steady flux assumption are different corresponding to the respective freeze-out 1 imits.

These in turn are governed by the largest cross section involved in the branch, which relates the so determined neutron density to the mode1 of cosner, Iben, and Truran (1980). In this way, the traditional s-process provides a check for the mode1, or possibly even allows the normalization of the time dependence of the neutron density to the observed abundances. We discuss this effect with an example of the branchings-at $85_{\mathrm{Kr}}$ and $170 \mathrm{Tm}$.

The largest cross section relevant for the ${ }^{85} \mathrm{Kr}$ branching is $\sigma\left({ }^{86} \mathrm{Rb}\right)=476 \mathrm{mb}$. With $\sigma \tau=1$ this leads to $\tau=2.1 \times 10^{-3} \mathrm{mb}^{-1}$ which means in the pulsed s-process model that the ${ }^{85} \mathrm{Kr}$ branching froze out $5.5 \times 10^{7} \mathrm{sec}$ after the pulse started. At this point the corresponding neutron density is $\mathrm{n}_{\mathrm{n}}=5.3 \times 10^{8} \mathrm{~cm}^{-3}$. In the branching at ${ }^{170} \mathrm{Tm}$, freeze-out occurs at a later time $\left(t=8.25 \times 10^{7} \mathrm{sec}\right)$ because the determining cross section of $170_{\mathrm{Tm}}$ is calculated to be $2260 \mathrm{mb}$ (Holmes et al. 1976). For this branching, one therefore obtains a neutron density of $1.0 \times 10^{8} \mathrm{~cm}^{-3}$. These results are shown in Figure 7 as black points with error bars which reflect the estimated cross section uncertainties $( \pm 50 \%)$.

Comparing these results with the neutron densities derived with the conventional steady flux assumption we find surprisingly good agreement for the two investigated cases. From the ${ }^{85} \mathrm{Kr}$ branching we obtained in this work an effective neutron density of $(2 \pm 1) \times 10^{9} \mathrm{~cm}^{-3}$. For the $170_{\mathrm{Tm}}$ branching Beer et a1. (1981) derived a possible neutron density between $10^{7}$ and $4 \times 10^{7} \mathrm{~cm}^{-3}$. These authors pointed out that very 1ikely there is no significant thermal enhancement to be expected for the $B^{-}$-decay of ${ }^{170}$ Tm because none of the low 1ying states have any less-forbidden $B^{-}$-decays than the ground state. However, according to the calculations of Cosner and Truran (1980), this half-1ife might be indeed reduced at stellar temperatures and this would increase the estimated neutron density by one order of magnitude. In Figure 7 the above values are given by open bars. Although there is not perfect agreement, the concept 
of a time dependent neutron flux is clearly consistent with the estimates from s-process branchings. Before any conclusion can be made, complementary analyses are required for other branchings which are determined by different cross sections. With the theoretical cross sections of Holmes et al. (1976) such information could be obtained from the branchings at ${ }^{134} \mathrm{Cs}\left[\sigma\left({ }^{134} \mathrm{Cs}\right)=1300 \mathrm{mb}\right]$, at ${ }^{151} \mathrm{Sm}\left[\sigma\left({ }^{152} \mathrm{Eu}\right)=4500 \mathrm{mb}\right]$, or at ${ }^{160} \mathrm{~Tb}\left[\sigma\left({ }^{160} \mathrm{~Tb}\right)=3200 \mathrm{mb}\right]$. If the present evidence for the time-dependent neutron flux could be confirmed this would certainly improve the general understanding of $\underline{s}$-process nucleosynthesis.

\section{CONCLUSIONS AND RECOMMENDATIONS}

With the improved capture cross sections available at present, we have

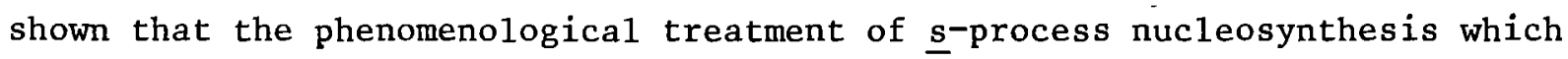
assumes the traditional idea of a steady neutron flux and an exponential fluence distribution works surprising1y well. In particular, good agreement was found between the calculated $\sigma \mathrm{N}(\mathrm{A})$-distribution and the ensemble of empirical $\sigma \mathrm{N}_{\mathrm{s}}$-values of pure s-process nuclei. This result is further confirmed if we subtract the so determined s-process abundances from the solar abundance distribution; again, good agreement is obtained between the resulting abundance distribution " $\mathrm{N}_{\mathrm{r}}$ " which is predominantly due to the $\underline{r}$-process and the abundances of pure $\underline{r}$-process nuclei.

This simple phenomenological model suggests two different modes of s-process synthesis, one which is characterized by a large seed abundance and weak neutron fluences and another one where a smaller seed was exposed to stronger irradiations. The model defines important average parameters for the two s-process modes, e.g. the mean neutron irradiations $\tau_{01}$ and $\tau_{02}$, the fractions $f_{1}$ and $f_{2}$ of the solar system abundance of ${ }^{56} \mathrm{Fe}$ which are required as seed, and a1so the average numbers of neutrons captured per ${ }^{56} \mathrm{Fe}$ seed nucleus.

We have shown that the effect of the s-process on the abundances in the mass region $\mathrm{A}<70$ is compatible with the observed abundances. For the elements around iron, the respective s-process abundances account for most of the deficiencies obtained in explosive nuclear burning. In the mass region below iron where the abundant alpha nuclei like ${ }^{32} \mathrm{~s},{ }^{36} \mathrm{Ar}$, or ${ }^{40} \mathrm{Ca}$ are followed by very rare neighbors, our calculations yield s-process abundances which never exceed the solar values. So far, our results are consistent with observation over the entire periodic table. 
The average phenomenological s-process parameters constitute important constraints for more detailed astrophysical models of possible s-process sites. Among these, the calculations carried out for a thermally pulsed He-burning shell in red giant stars seem to be successful in reproducing our results. In this context, s-process branchings are particularly useful for investigating a possible time dependence of the neutron flux as was discussed for the examples of the ${ }^{85} \mathrm{Kr}$ and the ${ }^{170} \mathrm{Tm}$ branching. However, for a conclusive discussion, these analyses must be carried out with better accuracy and for more branchings as well.

In spite of the overall agreement between calculated and empirical abundances, there are local discrepancies and gaps which need to be clarified and for which additional or more accurate information is required. Problems with elemental abundances have been identified for $\mathrm{Te}, \mathrm{W}$, and Hg which should be reconsidered according to new results from the analysis of meteorites. Another problem is certain1y the p-process contribution in the Mo-isotopes for which the different $\underline{p}$-process models are severely discrepant. If this contribution is significant, then ${ }^{96}$ Mo cannot be considered as an s-on1y isotope.

As far as neutron cross sections and decay parameters are concerned, one might find that the available data are sufficient for a global calculation of the $\sigma N_{s}$-curve. But for the decomposition into $\underline{s}_{-}^{-}$and $\underline{r}-p r o c e s s$ abundances, many cross sections are not sufficiently accurate. A1so for some s-only isotopes, the available measurements are either highly discordant (e.g. ${ }^{150} \mathrm{Sm}$ ) or the experimental value leads to a large deviation from the calculated $\sigma \mathrm{N}_{\mathrm{s}}$-curve (e.g. ${ }^{154} \mathrm{Gd}$ ). These two cases should be reinvestigated carefully. Most urgently, however, improved accuracy for the cross sections are required for the analysis of $\underline{s}$-process branchings. This is the more important, as such branchings are clues to many details of the s-process.

In addition, theoretical calculations of unmeasured cross sections should be further pursued, preferably with sophisticated methods such as those that are used to assess neutron data for reactors by taking into account the local behavior of the relevant input parameters of neighboring isotopes. 


\section{Acknowledgements :}

We appreciate very much the care and patience of Mrs. E. Maaß in preparing the manuscript. We would like to thank Drs. M.J. Harris and $B$. Fogelberg for providing us with their cross section results prior to publication as well as Drs. S.E. Woosley and W.M. Howard for the detailed computer printouts of their p-process calculations. D.D. Clayton is grateful for a Fulbright Fellowship in 1979-80 and the simultaneous hospitality of the Max-Planck-Institut für Kernphysik, Heidelberg, during his portion of this research, which is also supported by NASA NSG-7361.

\section{REFERENCES}

A1len, B.J., and Cohen, B.B. 1979, Aust. J. Phys., 32, 447.

Allen, B.J., and Mack1in, R.L. 1980, J. Phys. G: Nuc1. Phys., 6, 381.

Allen, B.J., Macklin, R.L., and Gibbons, J.H. 1971, Advances in Nuclear Physics, 4, 205, Baranger-Vogt, Eds., New York.

A1len, B.J., Macklin, R.L., Winters, R.R., and Fu, C.Y. 1973, Phys. Rev., C8, 1504.

Amiet, J.P., and Zeh, H.D. 1968, Zt.f. Phys., 217, 485. Audouze, J., and Truran, J.W., 1975, Ap.J., 202, 204.

Beer, H., and Käppeler, F. 1980, Phys. Rev., C 21, 534.

Beer, H., Käppeler, F., and Wisshak, K. 1981, in preparation.

Beer, H., Käppeler, F., Wisshak, K., and Ward, R.A. 1981, accepted by Ap.J.Supp1.

Beer, H., Spencer, R.R., and Ernst, A. 1974, Astron. \& Astrophys., $37,197$. 
Benzi, V., D'Orazi, R., and Reffo, G. 1973, I1 Nuovo Cimento, 13B, 226.

Bergman, A.A., and Romanov, S.A. 1974, Yad.Fiz., 20, 252; and 1975, Sov. J. Nucl. Phys., 20, 133.

B1ake, J.B., and Schramm, D.N. 1975, Ap.J., 197, 615.

Bo1deman, J.W., A1len, B.J., Musgrove, A.R. de L., and Mack1in, R.L. 1975, Nucl. Phys., A 246, 1. - 1977, Nuc1. Sci. Eng., 64, 744.

Burbidge, G.R., Burbidge, E.M., Fowler, W.A., and Hoyle, F. 1957, Rev. Mod. Phys., 29, 54.

Cameron, A.G.W. 1973, Space Sci. Rev., 15, 129.

- 1979, Ap.J. (Letters), 230, L53.

- 1981, in Essays in Nuclear Astrophysics, eds. C.A. Barnes, D.D. Clayton, and D.N. Schramm (Cambridge University Press: Cambridge 1981).

Chrien, R.E. 1975 , in Proc. Conf. on Nuclear Cross Sections and Technology, NBS Special Pub1ication 425, p. 139.

Clayton, D.D. 1964, Ap.J., 139, 637. - 1968, in Nucleosynthesis, ed. W.D. Arnett, C.J. Hansen, J.W. Truran and A.G.W. Cameron (New York: Gordon and Breach), p. 225.

-... 1976, Geochim. Cosmochim. Acta, 40, 563.

- 1978, Ap.J. (Letters), 224, L93. - 1981, in Essays in Nuclear Astrophysics, eds. C.A. Barnes, D.D. Clayton, and D.N. Schramm (Cambridge University Press: Cambridge 1981).

Clayton, D.D., Fowler, W.A. Hu11, T.E., and Zimmerman, B.A. 1961, Ann. Phys. 12, 331.

Clayton, D.D., and Rassbach, M.E. 1967, Ap.J., 148, 69. C1ayton, D.D., and Ward, R.A. 1974, Ap. J., 193, 397.

Conrad, J.H. 1976, unpublished Ph.D. thesis, University of Heidelberg. 
Cosner, K., Iben, I., Jr., and Truran, J.W. 1980, Ap. J. (Letters), 238, L91.

Cosner, K., and Truran, J.W. 1981, private communication.

Despain, K.H. 1980, Ap.J. (Letters), 236, L165.

Fogelberg, B., and Mack1in, R.L. 1981, private communication.

Fort, E., Thuong, T.Q., and Lafond, D. 1977, in Neutron Data of Structura1 Materials for Fast Reactors, ed. K.H. Böckhoff (Oxford: Pergamon Press); p. 190 .

Gibbons, J.H. 1968, priv. communication to the eds. of BNL-325, $2^{\text {nd }}$ edition.

Hainebach, K.L., Clayton, D.D., Árnett, W.D., and Woosley, S.E. 1974, Ap.J., 193, 157.

Harris, M.J. 1981, Ap.and Space Sci., to be pub1ished.

Ho1mes, J.A., Woosley, S.E., Fowler, W.A., and Zimmerman, B.A. 1976, Atomic Data and Nuclear Data Tables, 18, 305.

Hong, L.D., Beer, H., and Käppeler, F. 1979, Proc. XXII Colloque Int. d'Astrophysique, Liège, p. 79.

Iben, I., Jr., 1975a, Ap.J., 196, 525.

- 1975b, Ap.J., 196, 549.

Iben, I., Jr., and Truran, J.W. 1978, Ap.J., 220, 1980.

Käppeler, F. 1978, in Proc. Conf. on Neutron Physics and Nuclear Data for Reactors, Harwe11, United Kingdom, p. 809.

Kononov, V.N., Yurlov, B.D., Poletaev, E.D., and Timokhov, V.M. 1978, Sov.J.Nucl.Phys., 27, 5.

Lederer, C.M., and Shirley, V.S.1978, Table of Isotopes (New York: Wiley \& Sons). 
Leugers, B., Käppeler, F., Fabbri, F., and Reffo, G. 1979,

Proc. Int. Conf. on Nuclear Cross Sections for Technology, Knoxville, Tennessee, NBS special publication 594, 1980, p. 857.

Macklin, R.L. 1970, Ap.J., 162, 353.

Macklin, R.L., and Allen, B.J. 1971, Nuc1.Instr.Meth., 96, 509.

Mack1in, R.L. and Gibbons, J.H. 1967a, Phys.Rev., 159, 1007.

. 1967b, Ap.J., 149, 577.

Mack1in, R.L., Gibbons, J.H., and Inada, T. 1963, Nuc1.Phys., 43, 353.

Macklin, R.L., and Halperin, J. 1976, Phys.Rev.C, 14, 1389.

- 1980, Nucl.Sci.Eng., 73, 174.

Macklin, R.L., Halperin, J., and Winters, R.R. 1977, Ap.J., 217, 222.

. 1979, Nuc1.Sci.Eng., 71, 182.

Mack1in, R.L., and Winters, R.R. 1976, Ap.J., 208, 812.

Mizumoto, M., Raman, S., Macklin, R.L., Slaughter, G.G., Harvey, J.A., and Hamilton, J.H. 1979, Phys.Rev.C., 19, 335.

Murty, M.S., Siddappa, K., and Rao, J.R. 1973, J. Phys. Soc. Japan, 35, 8.

de L. Musgrove, A.R., A1len, B.J., and Boldeman, B.W. 1978, in Proc. Int. Conf. on Neutron Physics and Nuclear Data, Harwe11, Eng1and, p. 449 .

de L. Musgrove, A.R., A1len, B.J., Boldeman, J.W., Chan, D.M.H., and Macklin, R.L. 1976, Nucl. Phys., A 259, 365. . 1977, Nuc1. Phys., A 279, 317.

de L. Musgrove, A.R., Allen, B.J., Boldeman, J.W., and Mack1in, R.L. 1975, Nuc1. Phys., A 252, 301.

de L. Musgrove, A.R., Allen, B.J., and Mack1in, R.L. 1978, J.Phys.G, 4, 771 .

Palme, H. 1981, private communication. 
Palme, H., Suess, H.E., and Zeh, H.D. 1971, in Landolt-Börnstein, Neue Serie VI/2, chapters 3,4 .

Peters, J.G., Fowler, W.A., and Clayton, D.D. 1972, Ap.J., 173, 637.

Peterson, V.L., and Tripp, D.A. 1973, Ap.J., 184, 473.

Seeger, P.A., Fowler, W.A., and Clayton, D.D. 1965, Ap.J.Supp1., 11, 121.

Shorin, V.S., Kononov, V.N., and Poletaev, E.D. 1974, Sov.J.Nuc1.Phys., 19,5 .

Stroud, D.B. 1972, Ap.J. (Letters), 178, L93.

Suess, H.E., and Zeh, H.D. 1973, Ap. and Space Sci., 23, 173.

Truran, J.W. 1972, Ap.J., 177, 453.

Truran, J.W., and Iben, I., Jr. 1977, Ap.J., 216, 197.

U1rich, R.K. 1973, in Explosive Nucleosynthesis, eds. D.N. Schramm and W.D. Arnett (Austin: University of Texas Press), p. 139.

Vanpraet, G.J., Mack1in, R.L., A11en, B.J., and Winters, R.R. 1972, in Proc. Conf. on Nuclear Structure Study with Neutrons, Budapest, p. 20.

Wänke, H., Baddenhausen, H., Pa1me, H., and Spette1, B. 1974, Earth and Plan. Sci. Lett., 23, 1.

Ward, R.A. 1977, Ap.J., 216, 540.

Ward, R.A., and C1ayton, D.D. 1981, in preparation.

Ward, R.A., and Newman, M.J. 1978, Ap.J., 219, 195.

Ward, R.A., Newman, M.J., and Clayton, D.D. 1976, Ap.J.Supp1.31, 33.

Winters, R.R., Macklin, R.L., and Halperin, J. 1980, Phys. Rev., C21, 563. 
Wisshak, K., and Käppeler, F. 1978, Nuc1.Sci.Eng., 66, 363.

Woosley, S.E., Arnett, W.D., and C1ayton, D.D. 1973, Ap.J.Supp1., 26, 231.

Woosley, S.E., Fowler, W.A., Holmes, J.A., and Zimmerman, B.A.

1978, Atomic Data and Nuclear Data Tables, 22, 371.

Woosley, S.E., and Howard, W.M. 1978; Ap.J.Supp1. , 36, 285. 
Table 1 Maxwellian-averaged capture cross sections for $\mathrm{kT}=30 \mathrm{keV}$ of pure $\underline{s}$-process nuclei in the mass range $56<\mathrm{A}<209$. A11 values are in mb. Theoretically calculated cross sections are given without uncertainty. The uncertainties quoted for $\sigma_{\mathrm{s}}$ are due only to the cross sections and correspond to the error bars in Figure 2 . Solar abundances $\mathrm{N}_{\odot}$ are taken from Cameron (1981).

\begin{tabular}{|c|c|c|c|c|c|c|}
\hline & $\begin{array}{l}\text { A11en, } \\
\text { Macklin and } \\
\text { Gibbons } \\
\quad(1971)\end{array}$ & $\begin{array}{r}\text { Theoretical } \\
\text { Calculations }\end{array}$ & $\begin{array}{l}\text { Recent } \\
\text { Measure- } \\
\text { ments }\end{array}$ & $\operatorname{Ref}$ & $\begin{array}{c}\text { Recommended } \\
\text { Values }\end{array}$ & $\begin{array}{c}{ }_{0}^{\sigma N_{0}} \\
\left(S i \equiv 10^{6}\right) \\
(\mathrm{mb})\end{array}$ \\
\hline \multirow[t]{2}{*}{${ }^{58} \mathrm{Fe}$} & 4.5 & $9.5^{+}$ & $24+6$ & (1) & $18 \pm 3$ & $53460( \pm 17 \%)$ \\
\hline & & $6.6 * *$ & $15.9 \pm 1.5$ & (2) & & \\
\hline \multirow[t]{2}{*}{${ }^{70} \mathrm{Ge}$} & 84 & $\begin{array}{l}75^{*} \\
67^{+}\end{array}$ & & & $75 \pm 22$ & $1800(+30 \%)$ \\
\hline & & $82 * *$ & & & & \\
\hline \multirow[t]{2}{*}{${ }^{76} \mathrm{Se}$} & 100 & $\begin{array}{l}154^{*} \\
83^{+}\end{array}$ & & & $129 \pm 60$ & $779( \pm 50 \%)$ \\
\hline & & $126 * *$ & & & & \\
\hline \multirow[t]{2}{*}{${ }^{82} \mathrm{Kr}$} & 80 & $\begin{array}{l}197^{*} \\
122^{+}\end{array}$ & $105 \pm 15$ & (3) & $105 \pm 15$ & $501( \pm 14 \%)$ \\
\hline & & $79 * *$ & & & & \\
\hline \multirow[t]{2}{*}{${ }^{96}$ Mo } & $90 \pm 10$ & $\begin{array}{l}106 * \\
92+\end{array}$ & $\begin{array}{l}104 \pm 20 \\
112 \pm 16 \$\end{array}$ & $\begin{array}{l}(4) \\
(5)\end{array}$ & $108 \pm 13$ & $71.4( \pm 12 \%)$ \\
\hline & & $96 * *$ & & & & \\
\hline \multirow[t]{2}{*}{${ }^{100} \mathrm{Ru}$} & 290 & $\begin{array}{l}177^{*} \\
110^{+}\end{array}$ & $209 \pm 10$ & (6) & $209 \pm 10$ & $50.2( \pm 5 \%)$ \\
\hline & & $162 * *$ & & & & \\
\hline \multirow[t]{2}{*}{${ }^{104} \mathrm{Pd}$} & 270 & $\begin{array}{l}295^{*} \\
197^{+}\end{array}$ & $447 \pm 23$ & (7) & $447 \pm 23$ & $63.9(+5 \%)$ \\
\hline & & $315 * *$ & & & & \\
\hline \multirow[t]{2}{*}{${ }^{110} \mathrm{Cd}$} & 210 & $\begin{array}{l}386 * \\
220+\end{array}$ & $\begin{array}{l}270 \pm 30 \\
240+30\end{array}$ & $\begin{array}{l}(4) \\
(5)\end{array}$ & $255 \pm 30$ & $49.0( \pm 12 \%)$ \\
\hline & & $447 * *$ & & & & \\
\hline \multirow[t]{2}{*}{${ }^{116} \mathrm{Sn}$} & $100 \pm 15$ & $\begin{array}{l}119 * \\
176^{+}\end{array}$ & $96 \pm 19^{\#}$ & (8) & $97 \pm 19$ & $51.3( \pm 20 \%)$ \\
\hline & & $303 * *$ & & & & \\
\hline \multirow[t]{2}{*}{${ }^{122} \mathrm{Te}$} & $270 \pm 30$ & $\begin{array}{l}296 * \\
283+\end{array}$ & $\begin{array}{l}259+42^{\#} \\
351 \pm 70||\end{array}$ & $\begin{array}{l}(9) \\
(10)\end{array}$ & $305 \pm 60$ & $48.5(+20 \%)$ \\
\hline & & $382 * *$ & & & & \\
\hline
\end{tabular}


Table 1 (cont.)

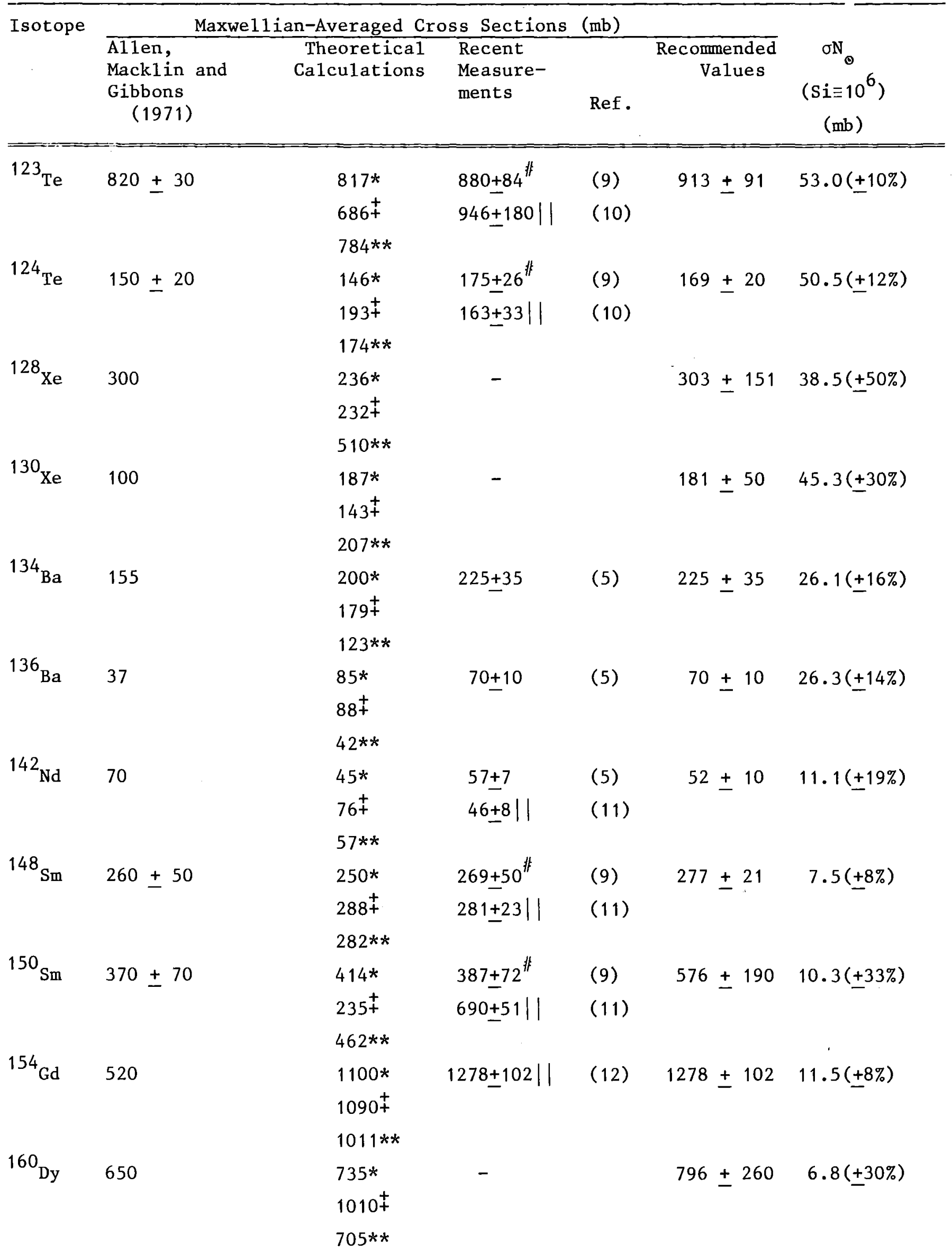


Table 1 (cont.)

\begin{tabular}{|c|c|c|c|c|c|c|}
\hline \multirow[t]{2}{*}{ Isotope } & \multicolumn{5}{|c|}{ Maxwe11ian-Averaged Cross Sections (mb) } & \multirow[b]{2}{*}{$\begin{array}{c}{ }_{\odot N_{\odot}} \\
\left(S i \equiv 10^{6}\right) \\
(\mathrm{mb})\end{array}$} \\
\hline & $\begin{array}{l}\text { A1len, } \\
\text { Mack1in and } \\
\text { Gibbons } \\
\quad(1971)\end{array}$ & $\begin{array}{r}\text { Theoretical } \\
\text { Calculations }\end{array}$ & $\begin{array}{l}\text { Recent } \\
\text { Measure- } \\
\text { ments }\end{array}$ & Ref. & $\begin{array}{c}\text { Recommended } \\
\text { Values }\end{array}$ & \\
\hline \multirow[t]{3}{*}{${ }^{170} \mathrm{Yb}$} & 510 & $1174 *$ & $790+60$ & (13) & $772 \pm 30$ & $4.7(+4 \%)$ \\
\hline & & $990^{+}$ & $766 \pm 30$ & (14) & & \\
\hline & & $861 * *$ & & & & \\
\hline \multirow[t]{2}{*}{${ }^{176} \mathrm{Lu}$} & $2250 \pm 200$ & $2680^{+}$ & $1718 \pm 85$ & (15) & $1718 \pm 85$ & - \\
\hline & & $2087 * *$ & & & & \\
\hline \multirow[t]{2}{*}{${ }^{176} \mathrm{Hf}$} & $640 \pm 160$ & $755^{+}$ & - & & $640 \pm 160$ & - \\
\hline & & $732 * *$ & & & & \\
\hline \multirow[t]{3}{*}{${ }^{186} \mathrm{os}$} & 330 & $530 *$ & $467 \pm 12$ & (16) & $467 \pm 20$ & $4.2(+4 \%)$ \\
\hline & & $734+$ & & & & \\
\hline & & $380 * *$ & . & & & \\
\hline \multirow[t]{3}{*}{${ }^{192} \mathrm{Pt}$} & 490 & $591 *$ & - & & $464 \pm 240$ & $5.1(+50 \%)$ \\
\hline & & $352+$ & & & & \\
\hline & & $322 * *$ & & & & \\
\hline \multirow[t]{2}{*}{${ }^{198} \mathrm{Hg}$} & 250 & $411+$ & - & & $460 \pm 230$ & $9.9( \pm 50 \%)$ \\
\hline & & $518 * *$ & & & & \\
\hline \multirow[t]{2}{*}{${ }^{204} \mathrm{~Pb}$} & $43 \pm 5$ & $50^{+}$ & $74+5$ & (17) & $59 \pm 20$ & $3.0( \pm 34 \%)$ \\
\hline & & $78 * *$ & & & & \\
\hline
\end{tabular}

*Benzi, d'Orazi, and Reffo (1973), + Woosley et a1. (19789,

$\mp$ Holmes et al. (1976), **Harris (1981)

References to measurements: (1) Hong, Beer, and Käppeler (1978),

(2) Allen and Macklin (1980), (3) Leugers et al. (1979), (4) Stroud (1972),

(5) Musgrove, Allen, and Boldeman (1978), (6) Macklin and Halperin (1980);

(7) Mack1in, Ha1perin, and Winters (1979), (8) Gibbons (1968), (9) Mack1in and

Gibbons (1967), (10) Bergman and Romanov (1974), (11) Kononov et a1. (1978),

(12) Shorin, Kononov, and Poletaev (1974), (11) Kononov et a1. (1978),

(14) Beer, Käppeler, Wisshak, and Ward (1981), (15) Beer and Käppeler (1980),

(16) Winters, Mack1in, and Halperin (1980), (17) Allen et al. (1973).

\$axwellian average calculated from differential data, "Renormalized with improved reference values, || Experimental data extrapolated by eq. (1). 
Table 2 Maxwe11ian-averaged capture cross sections for $\mathrm{kT}=30 \mathrm{keV}$ of nuclei with magic neutron numbers 50,82 and 126 and of nuclei belonging to the s-process branching at ${ }^{85} \mathrm{Kr}$. A1l values are in $\mathrm{mb}$. Theoretically. calculated cross sections are given without uncertainty. The uncertainties quoted for $\sigma N_{0}$ are due only to the cross sections and correspond to the error bars in Figure 2. Solar abundances $N_{0}$ are taken from Cameron (1981).

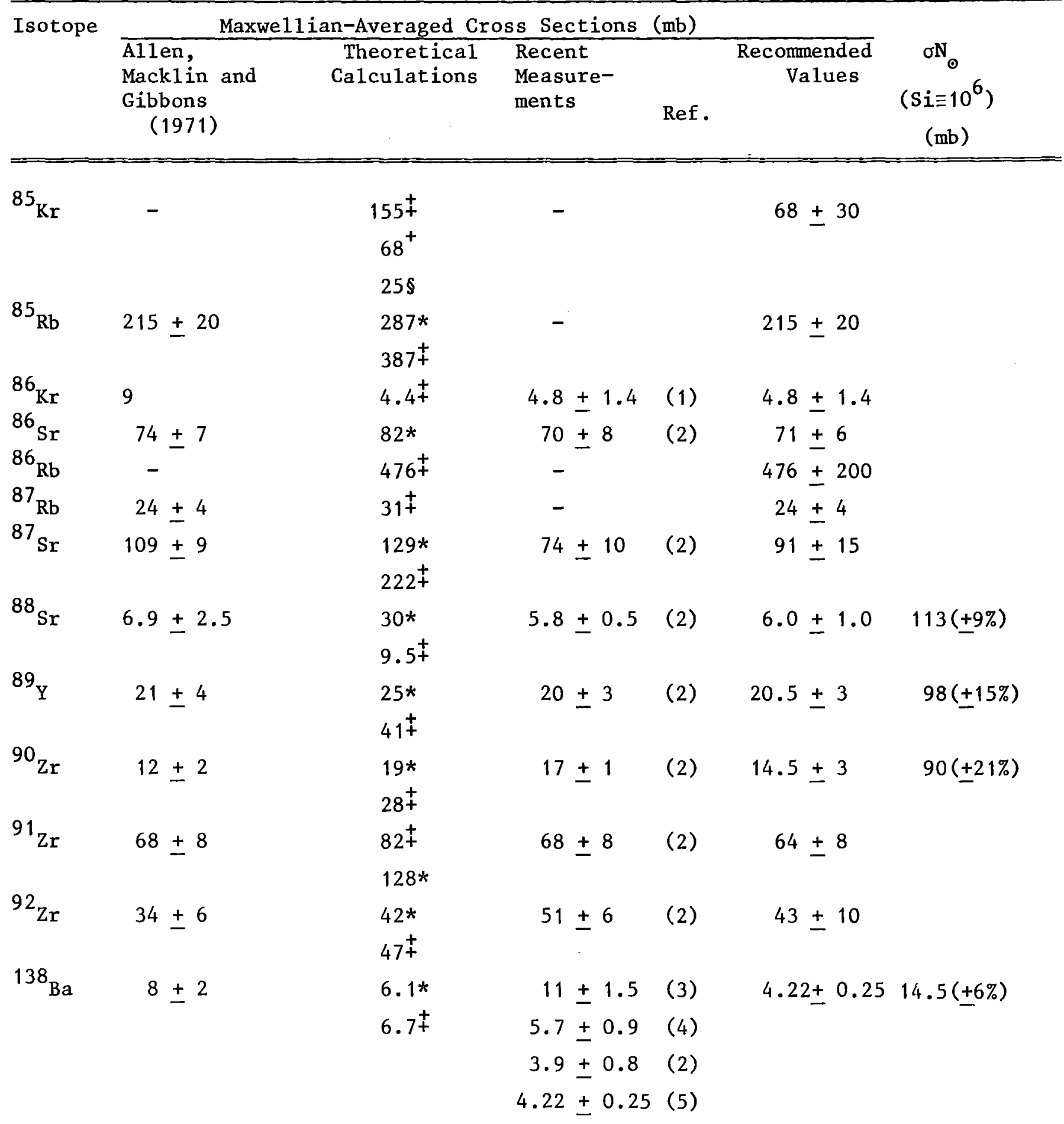


Table 2 (cont.)

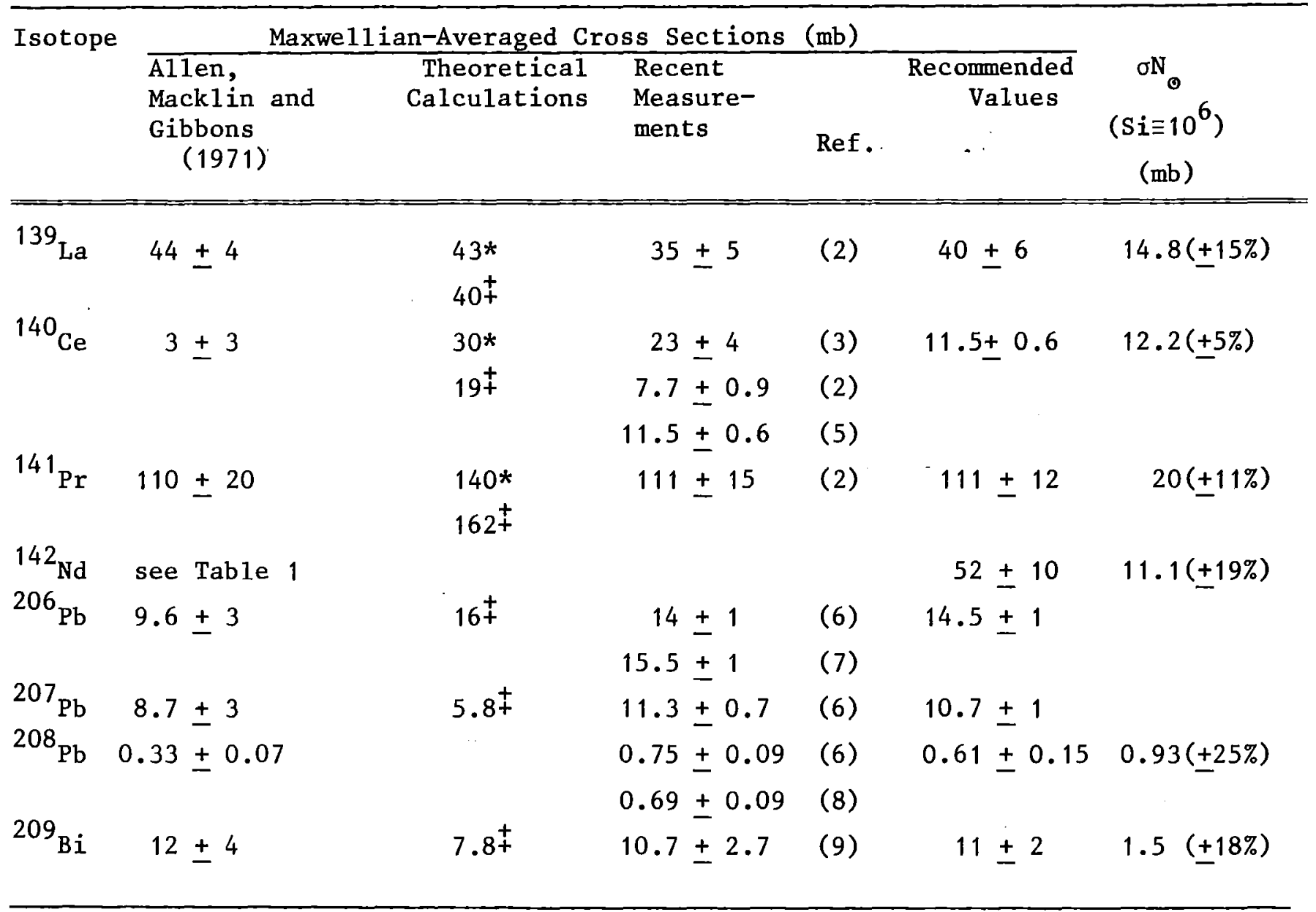

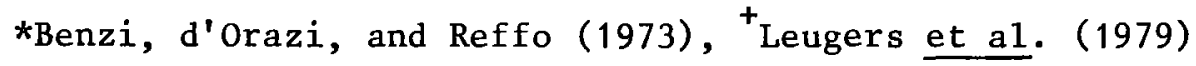

†Holmes et a1. (1976), §Harris (1981)

References to measurements: (1) Fogelberg and Mack1in (1981), (2) Musgrove, A1len, and Boldeman (1978), (3) Siddappa, Murty, and Rao (1973), (4) Musgrove et a1. (1975), (5) Beer and Käppeler (1980), (6) Allen et al. (1973), (7) Mizumuoto et al. (1979), (8) Macklin, Halperin and Winters (1977),

(9) Mack1in and Halperin (1976). 
Table 3 The parameters for the flux distribution $\rho(\tau)$ as calculated with different sets of solar abundances and Maxwel1ian-average cross sections. The values of the first line, which are based on the abundance table of Cameron (1981), are considered as the best estimate. The quoted uncertainties are estimated from the comparison with the results of other abundance tables. In the last column, the respective $x^{2}$-values are given to indicate the relative agreement between the calculated and the empirical oN ${ }_{s}$-curves.

\begin{tabular}{|c|c|c|c|c|c|c|}
\hline $\begin{array}{c}\text { Cross Sections } \\
\sigma\end{array}$ & $\begin{array}{l}\text { Source of } \\
\text { Solar Abun- } \\
\text { dances } \mathrm{N}_{0}\end{array}$ & $\mathrm{f}_{1}(\%)$ & ${ }_{01}^{\mathrm{T}}\left(\mathrm{mb}^{-1}\right)$ & $\mathrm{f} 2(\%)$ & ${ }^{\tau} 02{ }^{\left(\mathrm{mb}^{-1}\right)}$ & $\begin{array}{l}x^{2}+ \\
\left(10^{4}\right)\end{array}$ \\
\hline \multirow{4}{*}{$\begin{array}{l}\text { This compi- } \\
\text { lation }\end{array}$} & Cameron 1981 & $2.7+0.2$ & $0.056 \pm 0.005$ & $0.092+0.015$ & $0.240 \pm 0.010$ & 99 \\
\hline & $\begin{array}{l}\text { Cameron } 1973 \\
\text { Palme, }\end{array}$ & 2.7 & 0.058 & 0.125 & 0.225 & 79 \\
\hline & $\begin{array}{ll}\text { Suess } & 1981 \\
\& \text { Zeh } & \end{array}$ & 2.5 & 0.060 & 0.079 & 0.250 & 58 \\
\hline & $\begin{array}{l}\text { Suess } \\
\& \text { Zeh }\end{array}$ & 2.8 & 0.056 & 0.091 & 0.245 & 74 \\
\hline AMG* & Cameron 1981 & 2.8 & 0.052 & 0.10 & 0.250 & - \\
\hline $\begin{array}{l}\text { Ward and } \\
\text { Newman } \S\end{array}$ & Cameron 1973 & 135 & 0.05 & 0.35 & 0.25 & - \\
\hline
\end{tabular}

*Tabulated cross sections of Allen, Macklin, and Gibbons (1971) modified by

Tables 1 and 2 of this work and by the values of Beer, Spencer, and Ernst (1974).

\$Ward and Newman (1978) combined the estimated cross sections of A11en, Mack1in, and Gibbons (1971) with theoretically calculated values of Holmes et al. (1976).

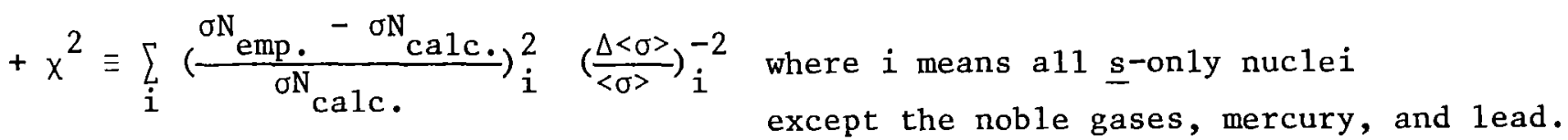
In addition, ${ }^{170} \mathrm{Yb}$ and ${ }^{186} \mathrm{Os}$ are omitted because they are likely members of a branching; ${ }^{96} \mathrm{Mo}$, because of its large p-process contribution is also omitted. 
Table 4 The average number of neutrons captured per ${ }^{56} \mathrm{Fe}$ seed nucleus. The values were calculated for the fluence distributions of Table III which are based on the cross section compilation of this work. The quoted uncertainties are estimated from the comparison with the results of other abundance tables.

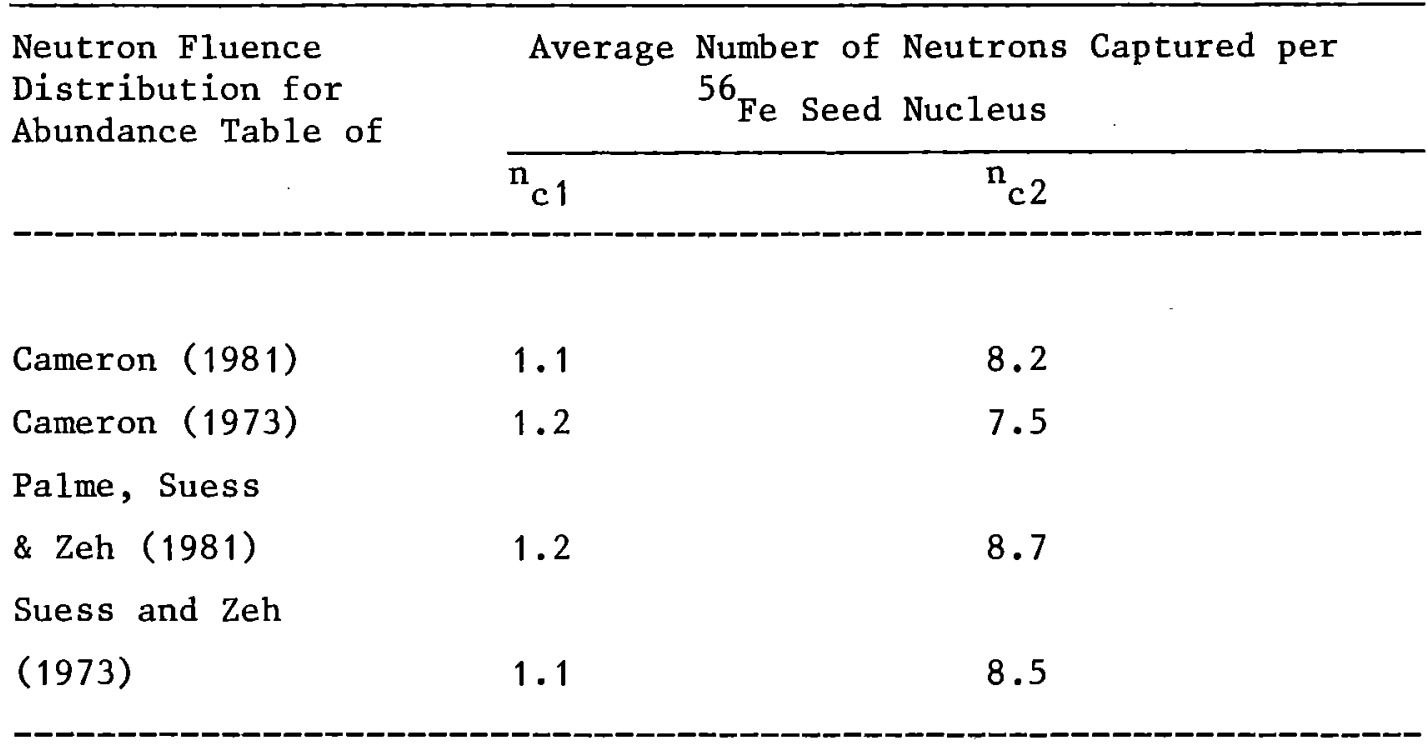


Table 5 Results from the analysis of the s-process branch at ${ }^{85} \mathrm{Kr}$ based on the respective best fit of the $\sigma \mathrm{N}_{s}$-curve to various abundance evaluations. The branching ratios $B_{n}$ were determined by normalizing the calculations to the empirical $\sigma \mathrm{N}_{\mathrm{s}}$-value of ${ }^{86} \mathrm{Sr}$. The last column lists all cases where we obtain an overproduction of calculated $\underline{s}$-process abundances which exceeds the solar value by more than the respective cross section uncertainty.

\begin{tabular}{|c|c|c|c|c|c|}
\hline \multirow{2}{*}{$\begin{array}{l}\text { Abundance } \\
\text { table used } \\
\text { for determining } \\
\text { the oN } \text {-curve }\end{array}$} & \multicolumn{2}{|c|}{$\begin{array}{l}\text { Calculated Branching } \\
\text { ratio } B_{n}(\%)\end{array}$} & \multirow{2}{*}{$\begin{array}{l}\text { Calculated } \\
\text { neutron } \\
\text { density } \\
\left(\mathrm{cm}^{-3}\right)\end{array}$} & \multirow{2}{*}{\multicolumn{2}{|c|}{$\begin{array}{l}\text { Overproduction } \\
\text { factors } \mathrm{N}_{\mathrm{S}}^{\mathrm{calc}} / \mathrm{N}_{0} \\
\text { for the most } \\
\text { severe cases }\end{array}$}} \\
\hline & $85_{\mathrm{Kr}}$ & ${ }^{86} \mathrm{Rb}$ & & & \\
\hline & & & & ${ }^{86} \mathrm{Kr}$ & ${ }^{87} \mathrm{Rb}$ \\
\hline Cameron (1981) & 0.431 & 0.328 & $1.8 \times 10^{9}$ & 2.4 & 3.2 \\
\hline Cameron (1973) & 0.426 & 0.298 & $1.6 \times 10^{9}$ & 2.3 & 3.3 \\
\hline $\begin{array}{l}\text { Palme, Suess } \\
\& \text { Zeh (1981) }\end{array}$ & 0.412 & 0.245 & $1.1 \times 10^{9}$ & 3.5 & 2.3 \\
\hline Suess and & & & & & \\
\hline Zeh (1973) & 0.415 & 0.235 & $1.1 \times 10^{9}$ & 1.6 & 2.3 \\
\hline
\end{tabular}


Table 6 p-Process overproduction factors $N_{\text {(zone) }} / N_{\odot}$ according to Woosley and Howard (1978). The values for $\underline{s}-$ only isotopes were provided privately by them. The last column 1ists the Cameron (1981) abundances for $\underline{p}$-nuclei. Values in parenthesis are relative $\underline{p}$-process contributions which were calculated by comparing the respective overproduction factors with those of neighboring $\underline{\mathrm{p}}^{-n u c l e i}$.

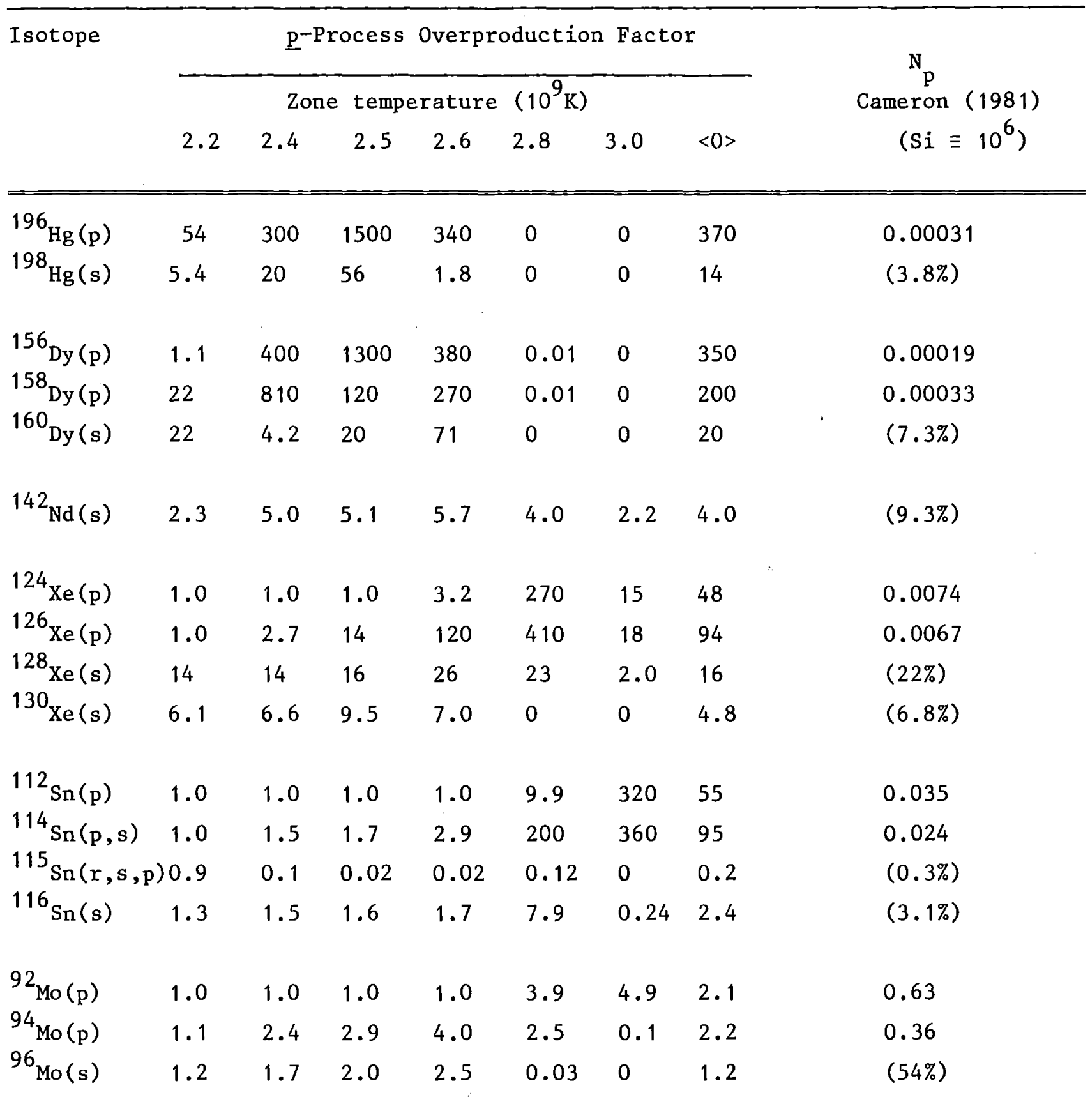


Table 7 Numerical results for the calculated oN -values, $\underline{s}$-process abundances $\mathrm{N}_{\mathrm{s}}$, and the absolute and fractional $\underline{\mathrm{r}}$-process residuals. A11 abundances are relative to $\mathrm{Si} \equiv 10^{6}$.

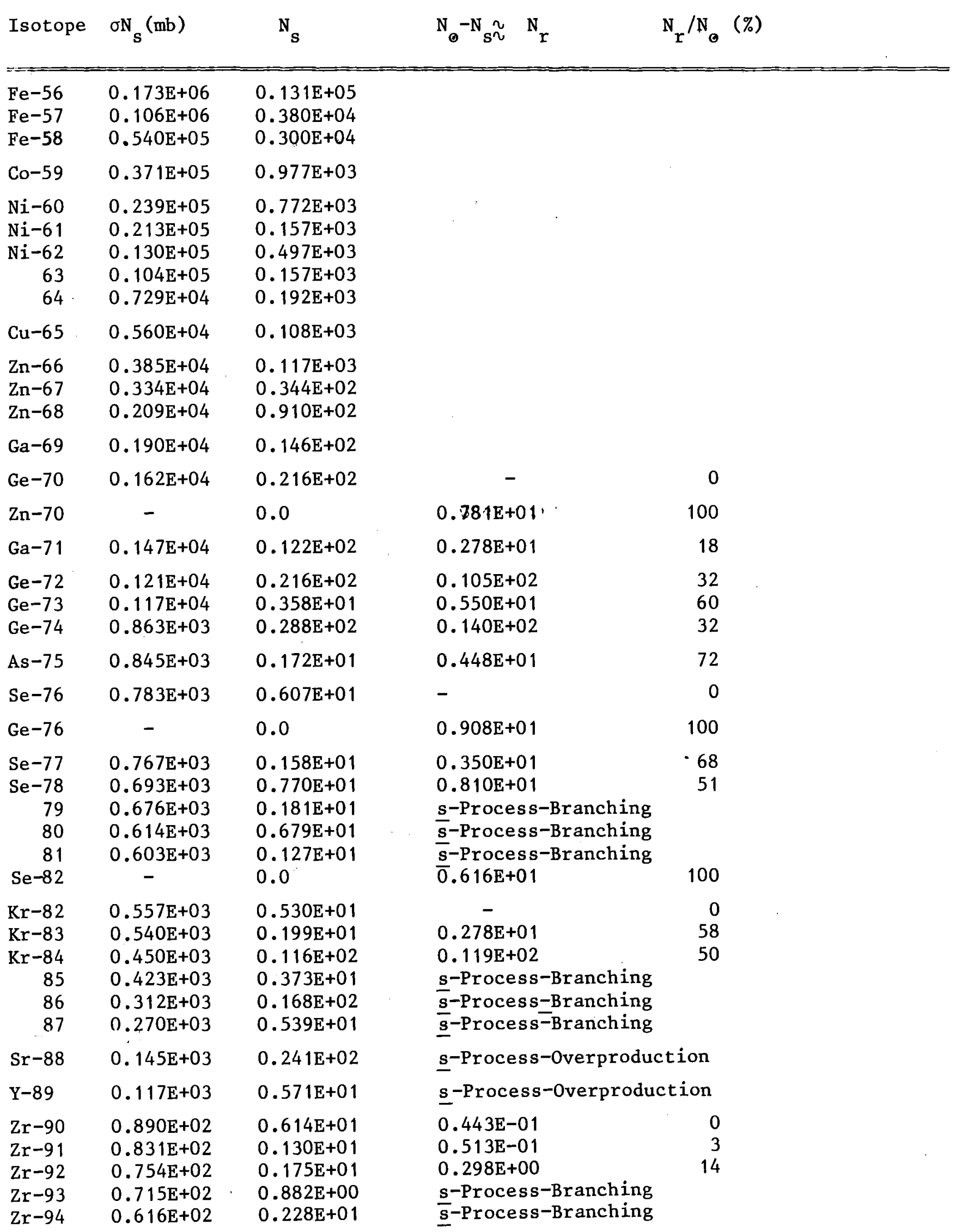


Table 7 (cont.)

\begin{tabular}{|c|c|c|c|c|}
\hline Isotope & $\sigma \mathrm{N}_{\mathrm{s}}(\mathrm{mb})$ & $\mathrm{N}_{\mathrm{s}}$ & $\mathrm{N}_{0}-\mathrm{N}_{s} \approx \mathrm{N}_{\mathrm{r}}$ & $\mathrm{N}_{\mathrm{r}} / \mathrm{N}_{\odot} \quad(\%)$ \\
\hline $\begin{array}{l}\text { Mo-95 } \\
\text { Mo-96 }\end{array}$ & $\begin{array}{l}0.610 \mathrm{E}+02 \\
0.587 \mathrm{E}+02\end{array}$ & $\begin{array}{l}0.142 E+00 \\
0.543 E+00\end{array}$ & $\begin{array}{c}0.487 \mathrm{E}+00 \\
-\end{array}$ & $\begin{array}{r}77 \\
0\end{array}$ \\
\hline $\mathrm{Zr}-96$ & - & 0.0 & $0.340 \mathrm{E}+00$ & 100 \\
\hline $\begin{array}{r}\text { Mo-97 } \\
\text { Mo-98 } \\
99\end{array}$ & $\begin{array}{l}0.579 \mathrm{E}+02 \\
0.560 \mathrm{E}+02 \\
0.557 \mathrm{E}+02\end{array}$ & $\begin{array}{l}0.166 E+00 \\
0.445 E+00 \\
0.870 E-01\end{array}$ & $\begin{array}{l}0.212 \mathrm{E}+00 \\
0.506 \mathrm{E}+00 \\
\text { s-Process-Branching }\end{array}$ & $\begin{array}{l}56 \\
53\end{array}$ \\
\hline$R u-100$ & $0.545 \mathrm{E}+02$ & $0.265 \mathrm{E}+00$ & - & 0 \\
\hline Mo-100 & - & 0.0 & $0.385 \mathrm{E}+00$ & 100 \\
\hline $\begin{array}{l}\mathrm{Ru}-101 \\
\mathrm{Ru}-102\end{array}$ & $\begin{array}{l}0.543 \mathrm{E}+02 \\
0.531 \mathrm{E}+02\end{array}$ & $\begin{array}{l}0.537 \mathrm{E}-01 \\
0.281 \mathrm{E}+00\end{array}$ & $\begin{array}{l}0.270 \mathrm{E}+00 \\
0.320 \mathrm{E}+00\end{array}$ & $\begin{array}{l}83 \\
53\end{array}$ \\
\hline $\mathrm{Rh}-103$ & $0.529 \mathrm{E}+02$ & $0.493 \mathrm{E}-01$ & $0.351 \mathrm{E}+00$ & 87 \\
\hline$P d-104$ & $0.523 E+02$ & $0.146 \mathrm{E}+00$ & - & 0 \\
\hline $\mathrm{Ru}-104$ & - & 0.0 & $0.353 E+00$ & 100 \\
\hline $\begin{array}{r}P d-105 \\
P d-106 \\
107 \\
108\end{array}$ & $\begin{array}{l}0.521 \mathrm{E}+02 \\
0.515 \mathrm{E}+02 \\
0.513 \mathrm{E}+02 \\
0.507 \mathrm{E}+02\end{array}$ & $\begin{array}{l}0.438 \mathrm{E}-01 \\
0.135 \mathrm{E}+00 \\
0.540 \mathrm{E}-01 \\
0.147 \mathrm{E}+00\end{array}$ & $\begin{array}{l}0.246 \mathrm{E}+00 \\
0.220 \mathrm{E}+00 \\
\text { s-Process-Branching } \\
\text { s-Process-Branching }\end{array}$ & $\begin{array}{l}84 \\
62\end{array}$ \\
\hline $\mathrm{Ag}-109$ & $0.503 E+02$ & $0.812 \mathrm{E}-01$ & $0.144 \mathrm{E}+00$ & 63 \\
\hline $\mathrm{Cd}-110$ & $0.495 \mathrm{E}+02$ & $0.194 \mathrm{E}+00$ & - & 0 \\
\hline$P d-110$ & - & 0.0 & $0.154 \mathrm{E}+00$ & 100 \\
\hline $\begin{array}{l}C d-1 \\
C d-11 \\
C d-11 \\
C d-114\end{array}$ & $\begin{array}{l}0.492 \mathrm{E}+02 \\
0.483 \mathrm{E}+02 \\
0.479 \mathrm{E}+02 \\
0.467 \mathrm{E}+02\end{array}$ & $\begin{array}{l}0.789 \mathrm{E}-01 \\
0.207 \mathrm{E}+00 \\
0.842 \mathrm{E}-01 \\
0.295 \mathrm{E}+00\end{array}$ & $\begin{array}{l}0.120 \mathrm{E}+00 \\
0.166 \mathrm{E}+00 \\
0.107 \mathrm{E}+00 \\
0.152 \mathrm{E}+00\end{array}$ & $\begin{array}{l}60 \\
44 \\
55 \\
33\end{array}$ \\
\hline $\operatorname{In}-115$ & $0.464 E+02$ & $0.617 \mathrm{E}-01$ & $0.121 \mathrm{E}+00$ & 66 \\
\hline$S n-116$ & $0.445 E+02$ & $0.458 \mathrm{E}+00$ & - & 0 \\
\hline$C d-116$ & - & 0.0 & $0.117 \mathrm{E}+00$ & 100 \\
\hline $\begin{array}{l}S n-117 \\
S n-118 \\
S n-119 \\
S n-120\end{array}$ & $\begin{array}{l}0.440 \mathrm{E}+02 \\
0.413 \mathrm{E}+02 \\
0.406 \mathrm{E}+02 \\
0.375 \mathrm{E}+02\end{array}$ & $\begin{array}{l}0.105 \mathrm{E}+00 \\
0.655 \mathrm{E}+00 \\
0.156 \mathrm{E}+00 \\
0.749 \mathrm{E}+00\end{array}$ & $\begin{array}{l}0.177 \mathrm{E}+00 \\
0.234 \mathrm{E}+00 \\
0.161 \mathrm{E}+00 \\
0.471 \mathrm{E}+00\end{array}$ & $\begin{array}{l}62 \\
26 \\
50 \\
38\end{array}$ \\
\hline$S b-121$ & $0.373 E+02$ & $0.442 \mathrm{E}-01$ & $0.133 E+00$ & 75 \\
\hline $\mathrm{Te}-122$ & $0.368 \mathrm{E}+02$ & $0.121 \mathrm{E}+00$ & - & 0 \\
\hline$S n-122$ & - & 0.0 & $0.175 \mathrm{E}+00$ & 100 \\
\hline $\mathrm{Te}-123$ & $0.366 \mathrm{E}+02$ & $0.401 \mathrm{E}-01$ & - & 0 \\
\hline $\mathrm{Sb}-123$ & - & 0.0 & $0.133 \mathrm{E}+00$ & 100 \\
\hline $\mathrm{Te}-124$ & $0.357 \mathrm{E}+02$ & $0.211 \mathrm{E}+00$ & - & 0 \\
\hline$S n-124$ & - & 0.0 & $0.220 \mathrm{E}+00$ & 100 \\
\hline
\end{tabular}


Table 7 (Cont.)

\begin{tabular}{|c|c|c|c|c|}
\hline Isotope & $\sigma N_{s}(m b)$ & $\mathrm{N}_{\mathrm{s}}$ & $\mathrm{N}_{0}-\mathrm{N}_{\mathrm{S}} \approx \mathrm{N}_{\mathrm{r}}$ & $\mathrm{N}_{\mathrm{r}} / \mathrm{N}_{\mathrm{o}}(\%)$ \\
\hline $\begin{array}{l}\mathrm{Te}-125 \\
\mathrm{Te}-126\end{array}$ & $\begin{array}{l}0.354 \mathrm{E}+02 \\
0.334 \mathrm{E}+02\end{array}$ & $\begin{array}{l}0.823 \mathrm{E}-01 \\
0.474 \mathrm{E}+00\end{array}$ & $\begin{array}{l}0.372 E+00 \\
0.750 E+00\end{array}$ & $\begin{array}{l}81 \\
61\end{array}$ \\
\hline$I-127$ & $0.332 E+02$ & $0.437 \mathrm{E}-01$ & $0.123 E+01$ & 96 \\
\hline $\mathrm{Xe}-128$ & $0.327 \mathrm{E}+02$ & $0.108 E+00$ & - & 0 \\
\hline $\mathrm{Te}-128$ & - & 0.0 & $0.208 \mathrm{E}+01$ & 100 \\
\hline $\begin{array}{l}X e-129 \\
X e-130\end{array}$ & $\begin{array}{l}0.325 \mathrm{E}+02 \\
0.318 \mathrm{E}+02\end{array}$ & $\begin{array}{l}0.603 \mathrm{E}-01 \\
0.176 \mathrm{E}+00\end{array}$ & $\begin{array}{c}0.155 E+01 \\
-\end{array}$ & $\begin{array}{l}96 \\
0\end{array}$ \\
\hline $\mathrm{Te}-130$ & - & 0.0 & $0.224 \mathrm{E}+01$ & 100 \\
\hline $\begin{array}{l}\mathrm{Xe}-131 \\
\mathrm{Xe}-132\end{array}$ & $\begin{array}{l}0.315 \mathrm{E}+02 \\
0.304 \mathrm{E}+02\end{array}$ & $\begin{array}{l}0.619 \mathrm{E}-01 \\
0.254 \mathrm{E}+00\end{array}$ & $\begin{array}{l}0.119 \mathrm{E}+01 \\
0.127 \mathrm{E}+01\end{array}$ & $\begin{array}{l}95 \\
83\end{array}$ \\
\hline $\mathrm{Cs}-133$ & $0.302 E+02$ & $0.428 \mathrm{E}-01$ & $0.347 \mathrm{E}+00$ & 89 \\
\hline $\mathrm{Ba}-134$ & $0.297 \mathrm{E}+02$ & $0.131 \mathrm{E}+00$ & - & 0 \\
\hline $\mathrm{Xe}-134$ & - & 0.0 & $0.590 \mathrm{E}+00$ & 100 \\
\hline $\begin{array}{l}\mathrm{Ba}-135 \\
\mathrm{Ba}-136\end{array}$ & $\begin{array}{l}0.294 \mathrm{E}+02 \\
0.279 \mathrm{E}+02\end{array}$ & $\begin{array}{l}0.627 \mathrm{E}-01 \\
0.359 \mathrm{E}+00\end{array}$ & $\begin{array}{c}0.253 \mathrm{E}+00 \\
-\end{array}$ & $\begin{array}{l}80 \\
0\end{array}$ \\
\hline $\mathrm{Xe}-136$ & - & 0.0 & $0.490 \mathrm{E}+00$ & 100 \\
\hline $\begin{array}{l}\mathrm{Ba}-137 \\
\mathrm{Ba}-138\end{array}$ & $\begin{array}{l}0.260 \mathrm{E}+02 \\
0.131 \mathrm{E}+02\end{array}$ & $\begin{array}{l}0.446 \mathrm{E}+00 \\
0.311 \mathrm{E}+01\end{array}$ & $\begin{array}{l}0.974 \mathrm{E}-01 \\
0.328 \mathrm{E}+00\end{array}$ & $\begin{array}{l}17 \\
9\end{array}$ \\
\hline La-139 & $0.119 \mathrm{E}+02$ & $0.298 \mathrm{E}+00$ & $0.721 \mathrm{E}-01$ & 19 \\
\hline $\mathrm{Ce}-140$ & $0.880 \mathrm{E}+01$ & $0.765 \mathrm{E}+00$ & $0.295 E+00$ & 27 \\
\hline $\operatorname{Pr}-141$ & $0.848 \mathrm{E}+01$ & $0.764 \mathrm{E}-01$ & $0.104 \mathrm{E}+00$ & 57 \\
\hline $\mathrm{Nd}-142$ & $0.787 \mathrm{E}+01$ & $0.151 \mathrm{E}+00$ & - & 0 \\
\hline $\mathrm{Ce}-142$ & - & 0.0 & $0.133 \mathrm{E}+00$ & 100 \\
\hline $\begin{array}{r}N d-143 \\
N d-144 \\
N d-145 \\
N d-146 \\
147\end{array}$ & $\begin{array}{l}0.775 \mathrm{E}+01 \\
0.729 \mathrm{E}+01 \\
0.722 \mathrm{E}+01 \\
0.698 \mathrm{E}+01 \\
0.695 \mathrm{E}+01\end{array}$ & $\begin{array}{l}0.292 \mathrm{E}-01 \\
0.112 \mathrm{E}+00 \\
0.158 \mathrm{E}-01 \\
0.607 \mathrm{E}-01 \\
0.605 \mathrm{E}-02\end{array}$ & $\begin{array}{l}0.669 \mathrm{E}-01 \\
0.759 \mathrm{E}-01 \\
0.498 \mathrm{E}-01 \\
0.753 \mathrm{E}-01 \\
\text { s-Process-Branching }\end{array}$ & $\begin{array}{l}69 \\
40 \\
75 \\
55\end{array}$ \\
\hline $\mathrm{Sm}-148$ & $0.685 \mathrm{E}+01$ & $0.247 \mathrm{E}-01$ & - & 0 \\
\hline $\mathrm{Nd}-148$ & - & 0.0 & $0.452 \mathrm{E}-01$ & 100 \\
\hline $\begin{array}{l}S m-149 \\
S m-150\end{array}$ & $\begin{array}{l}0.684 E+01 \\
0.679 E+01\end{array}$ & $\begin{array}{l}0.263 \mathrm{E}-02 \\
0.118 \mathrm{E}-01\end{array}$ & $\begin{array}{c}0.306 \mathrm{E}-01 \\
-\end{array}$ & $\begin{array}{l}92 \\
0\end{array}$ \\
\hline $\begin{array}{r}\mathrm{Nd}-150 \\
151 \\
152 \\
153\end{array}$ & $\begin{array}{c}- \\
0.679 \mathrm{E}+01 \\
0.672 \mathrm{E}+01 \\
0.671 \mathrm{E}+01\end{array}$ & $\begin{array}{l}0.0 \\
0.149 \mathrm{E}-02 \\
0.156 \mathrm{E}-01 \\
0.249 \mathrm{E}-02\end{array}$ & $\begin{array}{l}0.444 \mathrm{E}-01 \\
\text { s-Process-Branching } \\
\text { s-Process-Branching } \\
\underline{s}-\text { Process-Branching }\end{array}$ & 100 \\
\hline Gd-154 & $0.669 \mathrm{E}+01$ & $0.524 \mathrm{E}-02$ & - & 0 \\
\hline Sm-154 & - & 0.0 & $0.545 \mathrm{E}-01$ & 100 \\
\hline $\begin{array}{l}\mathrm{Gd}-155 \\
\mathrm{Gd}-156 \\
\mathrm{Gd}-157\end{array}$ & $\begin{array}{l}0.668 \mathrm{E}+01 \\
0.663 \mathrm{E}+01 \\
0.661 \mathrm{E}+01\end{array}$ & $\begin{array}{l}0.246 \mathrm{E}-02 \\
0.119 \mathrm{E}-01 \\
0.452 \mathrm{E}-02\end{array}$ & $\begin{array}{l}0.594 \mathrm{E}-01 \\
0.741 \mathrm{E}-01 \\
0.614 \mathrm{E}-01\end{array}$ & $\begin{array}{l}96 \\
86 \\
93\end{array}$ \\
\hline
\end{tabular}


Table 7 (cont.)

\begin{tabular}{|c|c|c|c|c|}
\hline Isotope & $\sigma N_{s}(m b)$ & $\mathrm{N}_{\mathrm{s}}$ & $\mathrm{N}_{0}-\mathrm{N}_{s} \approx \mathrm{N}_{\mathrm{r}}$ & $\mathrm{N}_{\mathrm{r}} / \mathrm{N}_{\odot}$ \\
\hline Gd-158 & $0.655 \mathrm{E}+01$ & $0.154 \mathrm{E}-01$ & $0.886 \mathrm{E}-01$ & 85 \\
\hline $\mathrm{Tb}-159$ & $0.654 \mathrm{E}+01$ & $0.323 \mathrm{E}-02$ & $0.728 \mathrm{E}-01$ & .95 \\
\hline Dy -160 & $0.651 E+01$ & $0.818 \mathrm{E}-02$ & - & 0 \\
\hline $\mathrm{Gd}-160$ & - & 0.0 & $0.920 \mathrm{E}-01$ & 100 \\
\hline $\begin{array}{l}\text { Dy-161 } \\
\text { Dy-162 } \\
\text { Dy-163 } \\
\text { Dy-164 }\end{array}$ & $\begin{array}{l}0.650 \mathrm{E}+01 \\
0.644 \mathrm{E}+01 \\
0.643 \mathrm{E}+01 \\
0.628 \mathrm{E}+01\end{array}$ & $\begin{array}{l}0.232 \mathrm{E}-02 \\
0.137 \mathrm{E}-01 \\
0.402 \mathrm{E}-02 \\
0.349 \mathrm{E}-01\end{array}$ & $\begin{array}{l}0.676 \mathrm{E}-01 \\
0.808 \mathrm{E}-01 \\
0.884 \mathrm{E}-01 \\
0.691 \mathrm{E}-01\end{array}$ & $\begin{array}{l}96 \\
85 \\
95 \\
66\end{array}$ \\
\hline Ho- 165 & $0.626 E+01$ & $0.493 \mathrm{E}-02$ & $0.871 \mathrm{E}-01$ & 94 \\
\hline $\begin{array}{l}\text { Er-166 } \\
\text { Er-167 } \\
\text { Er-168 }\end{array}$ & $\begin{array}{l}0.621 E+01 \\
0.620 E+01 \\
0.609 E+01\end{array}$ & $\begin{array}{l}0.120 \mathrm{E}-01 \\
0.431 \mathrm{E}-02 \\
0.251 \mathrm{E}-01\end{array}$ & $\begin{array}{l}0.648 \mathrm{E}-01 \\
0.484 \mathrm{E}-01 \\
0.372 \mathrm{E}-01\end{array}$ & $\begin{array}{l}84 \\
91 \\
59\end{array}$ \\
\hline $\operatorname{Tm}-169$ & $0.607 \mathrm{E}+01$ & $0.539 \mathrm{E}-02$ & $0.296 \mathrm{E}-01$ & 84 \\
\hline $\mathrm{Yb}-170$ & $0.604 \mathrm{E}+01$ & $0.782 \mathrm{E}-02$ & - & 0 \\
\hline $\mathrm{Er}-170$ & - & 0.0 & $0.342 \mathrm{E}-01$ & 100 \\
\hline $\begin{array}{l}\mathrm{Yb}-171 \\
\mathrm{Yb}-172 \\
\mathrm{Yb}-173 \\
\mathrm{Yb}-174\end{array}$ & $\begin{array}{l}0.602 \mathrm{E}+01 \\
0.596 \mathrm{E}+01 \\
0.594 \mathrm{E}+01 \\
0.580 \mathrm{E}+01\end{array}$ & $\begin{array}{l}0.415 \mathrm{E}-02 \\
0.145 \mathrm{E}-01 \\
0.686 \mathrm{E}-02 \\
0.331 \mathrm{E}-01\end{array}$ & $\begin{array}{l}0.245 \mathrm{E}-01 \\
0.291 \mathrm{E}-01 \\
0.254 \mathrm{E}-01 \\
0.306 \mathrm{E}-01\end{array}$ & $\begin{array}{l}85 \\
66 \\
78 \\
47\end{array}$ \\
\hline $\begin{array}{r}\mathrm{Lu}-175 \\
176\end{array}$ & $\begin{array}{l}0.578 \mathrm{E}+01 \\
0.576 \mathrm{E}+01\end{array}$ & $\begin{array}{l}0.457 \mathrm{E}-02 \\
0.538 \mathrm{E}-02\end{array}$ & $\begin{array}{l}0.295 \mathrm{E}-01 \\
\text { s-Process-Branching }\end{array}$ & 86 \\
\hline $\mathrm{Yb}-176$ & - & 0.0 & $0.255 \mathrm{E}-01$ & 100 \\
\hline $\begin{array}{l}\mathrm{Hf}-177 \\
\mathrm{Hf}-178 \\
\mathrm{Hf}-179 \\
\mathrm{Hf}-180\end{array}$ & $\begin{array}{l}0.574 \mathrm{E}+01 \\
0.567 \mathrm{E}+01 \\
0.566 \mathrm{E}+01 \\
0.553 \mathrm{E}+01\end{array}$ & $\begin{array}{l}0.383 E-02 \\
0.172 E-01 \\
0.420 E-02 \\
0.316 E-01\end{array}$ & $\begin{array}{l}0.277 \mathrm{E}-01 \\
0.289 \mathrm{E}-01 \\
0.192 \mathrm{E}-01 \\
0.283 \mathrm{E}-01\end{array}$ & $\begin{array}{l}87 \\
62 \\
82 \\
47\end{array}$ \\
\hline $\mathrm{Ta}-181$ & $0.550 \mathrm{E}+01$ & $0.687 \mathrm{E}-02$ & $0.131 \mathrm{E}-01$ & 65 \\
\hline $\begin{array}{l}W-182 \\
W-183 \\
W-184\end{array}$ & $\begin{array}{l}0.543 \mathrm{E}+01 \\
0.539 \mathrm{E}+01 \\
0.531 \mathrm{E}+01\end{array}$ & $\begin{array}{l}0.169 \mathrm{E}-01 \\
0.980 \mathrm{E}-02 \\
0.207 \mathrm{E}-01\end{array}$ & $\begin{array}{l}0.623 \mathrm{E}-01 \\
0.334 \mathrm{E}-01 \\
0.712 \mathrm{E}-01\end{array}$ & $\begin{array}{l}78 \\
77 \\
77\end{array}$ \\
\hline $\begin{array}{l}\mathrm{Re}-185 \\
0 s-186\end{array}$ & $\begin{array}{l}0.529 \mathrm{E}+01 \\
0.524 \mathrm{E}+01\end{array}$ & $\begin{array}{l}0.346 \mathrm{E}-02 \\
0.116 \mathrm{E}-01\end{array}$ & $\begin{array}{l}- \\
-\end{array}$ & $\begin{array}{l}81 \\
0\end{array}$ \\
\hline W-186 & - & 0.0 & $0.852 \mathrm{E}-01$ & 100 \\
\hline $0 s-187$ & $0.522 \mathrm{E}+01$ & $0.566 \mathrm{E}-02$ & - & 0 \\
\hline $\operatorname{Re}-187$ & - & 0.0 & $0.348 \mathrm{E}-01$ & 100 \\
\hline $\begin{array}{l}0 s-188 \\
0 s-189 \\
0 s-190\end{array}$ & $\begin{array}{l}0.517 \mathrm{E}+01 \\
0.516 \mathrm{E}+01 \\
0.509 \mathrm{E}+01\end{array}$ & $\begin{array}{l}0.128 E-01 \\
0.336 E-02 \\
0.172 E-01\end{array}$ & $\begin{array}{l}0.789 \mathrm{E}-01 \\
0.108 \mathrm{E}+00 \\
0.165 \mathrm{E}+00\end{array}$ & $\begin{array}{l}86 \\
96 \\
90\end{array}$ \\
\hline $\operatorname{Ir}-191$ & $0.507 E+01$ & $0.383 \mathrm{E}-02$ & $0.265 \mathrm{E}+00$ & 98 \\
\hline Pt -192 & $0.503 \mathrm{E}+01$ & $0.108 \mathrm{E}-01$ & - & 0 \\
\hline $0 s-192$ & - & 0.0 & $0.283 \mathrm{E}+00$ & 100 \\
\hline
\end{tabular}


Table 7 (cont.)

\begin{tabular}{|c|c|c|c|c|}
\hline Isotope & $\sigma \mathbb{N}_{\mathbf{s}}(\mathrm{mb})$ & $\mathbf{N}_{\mathbf{s}}$ & $\mathrm{N}_{0}-\mathrm{N}_{\mathrm{s}} \approx \mathrm{N}_{\mathrm{r}}$ & $\mathrm{N}_{\mathrm{r}} / \mathrm{N}_{\odot} \quad(\%)$ \\
\hline 193 & $0.500 \mathrm{E}+01$ & $.0 .624 \mathrm{E}-02$ & \multicolumn{2}{|c|}{ s-Process-Branching } \\
\hline $\begin{array}{l}\text { Pt }-194 \\
\text { Pt }-195 \\
\text { Pt-196 }\end{array}$ & $\begin{array}{l}0.495 \mathrm{E}+01 \\
0.493 \mathrm{E}+01 \\
0.481 \mathrm{E}+01\end{array}$ & $\begin{array}{l}0.128 \mathrm{E}-01 \\
0.474 \mathrm{E}-02 \\
0.300 \mathrm{E}-01\end{array}$ & $\begin{array}{l}0.451 \mathrm{E}+00 \\
0.472 \mathrm{E}+00 \\
0.327 \mathrm{E}+00\end{array}$ & $\begin{array}{l}97 \\
99 \\
91\end{array}$ \\
\hline $\mathrm{Au}-197$ & $0.477 E+01$ & $0.783 \mathrm{E}-02$ & $0.202 E+00$ & 96 \\
\hline $\mathrm{Hg}-198$ & $0.473 E+01$ & $0.103 \mathrm{E}-01$ & - & 0 \\
\hline Pt -198 & - & 0.0 & $0.102 E+00$ & 100 \\
\hline $\begin{array}{l}\mathrm{Hg}-199 \\
\mathrm{Hg}-200 \\
\mathrm{Hg}-201 \\
\mathrm{Hg}-202\end{array}$ & $\begin{array}{l}0.467 \mathrm{E}+01 \\
0.441 \mathrm{E}+01 \\
0.428 \mathrm{E}+01 \\
0.392 \mathrm{E}+01\end{array}$ & $\begin{array}{l}0.129 \mathrm{E}-01 \\
0.635 \mathrm{E}-01 \\
0.329 \mathrm{E}-01 \\
0.872 \mathrm{E}-01\end{array}$ & \multicolumn{2}{|c|}{$\begin{array}{l}0.225 \mathrm{E}-01 \\
\text { s-Process-Overproduction } \\
\underline{\underline{s}}-\text { Process-Overproduction } \\
\underline{\mathbf{s}} \text {-Process-Overproduction }\end{array}$} \\
\hline $\mathrm{T} 1-203$ & $0.382 E+01$ & $0.255 \mathrm{E}-01$ & $0.306 \mathrm{E}-01$ & 54 \\
\hline $\mathrm{Pb}-204$ & $0.357 \mathrm{E}+01$ & $0.606 \mathrm{E}-01$ & - & 0 \\
\hline $\mathrm{Hg}-204$ & - & 0.0 & $0.960 \mathrm{E}-02$ & 100 \\
\hline $\mathrm{Pb}-205$ & $0.334 \mathrm{E}+01$ & $0.576 \mathrm{E}-01$ & $0.764 \mathrm{E}-01$ & 57 \\
\hline $\begin{array}{l}\mathrm{Pb}-206 \\
\mathrm{~Pb}-207 \\
\mathrm{~Pb}-208\end{array}$ & $\begin{array}{l}0.260 \mathrm{E}+01 \\
0.189 \mathrm{E}+01 \\
0.245 \mathrm{E}+00\end{array}$ & $\begin{array}{l}0.180 \mathrm{E}+00 \\
0.176 \mathrm{E}+00 \\
0.402 \mathrm{E}+00\end{array}$ & $\begin{array}{l}0.310 \mathrm{E}+00 \\
0.360 \mathrm{E}+00 \\
0.112 \mathrm{E}+01\end{array}$ & $\begin{array}{l}63 \\
67 \\
73\end{array}$ \\
\hline $\mathrm{Bi}-209$ & $0.17 \cdot 9 \mathrm{E}+00$ & $0.163 E-01$ & $0.124 \mathrm{E}+00$ & 88 \\
\hline
\end{tabular}


Table 8 s-process abundances $\left(\mathrm{Si}=10^{6}\right)$ in the Ar-K-Ca-region

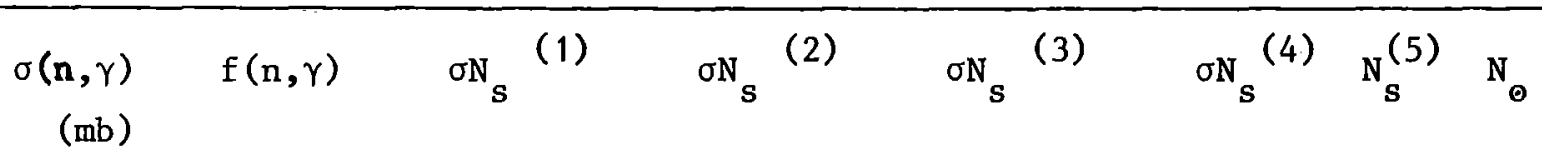

\begin{tabular}{|c|c|c|c|c|c|c|c|c|}
\hline${ }^{36} \mathrm{Ar}$ & $6.7 *$ & 1 & & & 12523 & 12523 & 1870 & $8.93 \times 10^{4}$ \\
\hline${ }^{37} \mathrm{Cl}$ & $2.8 *$ & 1 & & & 1705 & 1705 & 609 & 1160 \\
\hline${ }^{38} \mathrm{Ar}$ & $2.6 *$ & 1 & & & 1326 & 1326 & 511 & $1.67 \times 10^{4}$ \\
\hline${ }^{39} \mathrm{~K}$ & $8.0 *$ & 0.71 & & & & 524 & 47 & \\
\hline${ }^{39}{ }_{K}$ & $16 \pm 2^{+}$ & 1 & & & 634 & & & 3258 \\
\hline & $3.6 *$ & 1 & & & & 81 & 23 & \\
\hline${ }^{40} \mathrm{~K}$ & $19 *$ & 0.22 & & & 531 & & & 4.8 \\
\hline${ }^{40} \mathrm{Ca}$ & $6.7+7^{\S}$ & 1 & 8498 & & & & 1268 & $6.06 \times 10^{4}$ \\
\hline${ }^{41} \mathrm{~K}$ & $22 \pm 3^{+}$ & & & & 168 & 44 & 2 & 241 \\
\hline${ }^{41} \mathrm{Ca}$ & $15 *$ & 0.041 & 8094 & & & & 22 & \\
\hline${ }^{42} \mathrm{Ca}$ & $15.6+2^{\S}$ & 1 & 1801 & 96 & 88 & 25 & 123 & 400 \\
\hline${ }^{43} \mathrm{Ca}$ & $62 \pm 7^{\S}$ & 1 & 1402 & 74 & 72 & 22 & 24 & 91 \\
\hline${ }^{44} \mathrm{Ca}$ & $15 \cdot 3+3^{\S}$ & 1 & 664 & 34 & 41 & 14 & 47 & 1290 \\
\hline${ }^{45} \mathrm{Ca}^{\#}$ & $14 *$ & 1 & 309 & 15 & 24 & 9 & 254 & \\
\hline${ }^{46} \mathrm{Ca}$ & $3.7 *$ & 1 & 68 & 3 & 9 & 4 & 20 & 2.06 \\
\hline
\end{tabular}

*Calculated cross sections from Woosley et al. (1978)

+ Allen, Mack1in, and Gibbons (1971)

$\$$ Musgrove et al. $(1976 ; 1977)$

\# ${ }^{45} \mathrm{Ca}$ was taken to be stable to maximize effect on ${ }^{46} \mathrm{Ca}$

(1) s-path from ${ }^{40} \mathrm{Ca}$ seed only, and only direct path through ${ }^{41} \mathrm{Ca}$

(2) s-path from ${ }^{42} \mathrm{Ca}$ seed on1y

(3) s-path from ${ }^{36,38} \mathrm{Ar}$ seed and from ${ }^{40} \mathrm{Ca}$ (via ${ }^{41} \mathrm{Ca}(\mathrm{n}, \alpha)$ ), letting ${ }^{39} \mathrm{Ar}$ decay

(4) to replace (3) if ${ }^{39} \mathrm{Ar}\left(\mathrm{T}_{1 / 2}=269 \mathrm{yr}\right)$ is effectively stable

(5) $\mathrm{N}_{\mathrm{s}}=\left(\sigma \mathrm{N}_{\mathrm{s}}(1)+\sigma \mathrm{N}_{\mathrm{s}}(2)+\sigma \mathrm{N}_{\mathrm{s}}(4)\right) / \sigma$ 
Figure Captions

Fig. 1. Left:

Schematic set-up for activation measurements of neutron capture cross sections using a kinematically collimated neutron beam.

Right, top: Decay curve of the neutron induced activity for the example of ${ }^{138} \mathrm{Ba}(n, \gamma){ }^{139} \mathrm{Ba}$. Confirmation of the half-life ensures identification of the proper decay line and background subtraction. Right, bottom: Approximation of the Maxwellian energy distribution of neutrons at $\mathrm{kT}=25 \mathrm{keV}$ (dashed 1ine) by the neutron spectrum produced via the ${ }^{7} \mathrm{Li}(\mathrm{p}, \mathrm{n})$ reaction during activation (histogram). The measured cross section corresponds directly to the Maxwellian average.

Fig. 2. The product of s-process abundance-times-cross-section as a function of mass number. The symbols correspond to empirical values for s-only isotopes (squares) or to neutron magic isotopes which are predominantly produced by the s-process (circles). The respective abundances are taken from the solar abundance table of Cameron (1981). Error bars include the cross section uncertainties only. The calculated solid lines correspond to the strong and weak component in the exponential neutron fluence distribution.

Fig. 3. The s-process flow through the mass region $84<\mathrm{A}<92$. Main branching points are shaded and the branching ratios (in percent) are indicated. Analysis of the ${ }^{85} \mathrm{Kr}$-branching yields a neutron density of $1.8 \times 10^{9} \mathrm{~cm}^{-3}$.

Fig. 4. The various components of the $\sigma \mathrm{N}_{\mathrm{s}}$-curve due to the branching points ${ }^{85} \mathrm{Kr}$ and ${ }^{86} \mathrm{Rb}$. Minor branchings at $89,90 \mathrm{Sr}$ are neglected. Note the significant discrepancy between the empirical value for ${ }^{86} \mathrm{Kr}$ and the respective calculated branch (dotted).

Fig. 5. Approximate r-process abundances derived as the difference between solar abundances (Cameron 1981) and calculated $\underline{s}^{-}$ process abundances. Abundance maxima are stressed by eye-guide 1ines. The pronounced odd-even effect below A 90 is illustrated by the dashed line (even isotopes) and the solid line (odd isotopes). The black squares are the solar abundances of $\underline{\mathrm{r}}$-only isotopes. 
Fig. 6. Comparison of solar abundances of the iron group isotopes (Cameron 1981) with the calculated s-process abundances and with results obtained in explosive nuclear burning (Woosley, Arnett, Clayton 1973). The differences between calculated and solar values on the left side of the peak might be due to spallation reactions.

Fig. 7. The time-dependent neutron density from a pulsed $\underline{s}$-process mode1 (Cosner, Iben, Truran 1980; solid line). The full circles represent the model estimates of neutron densities for the branchings at ${ }^{85} \mathrm{Kr}$ and ${ }^{170} \mathrm{Tm}$ whereas the open bars are the results of steady-flow branching analyses. The latter data seem to provide evidence for a pulsed $\underline{s}$-process. 


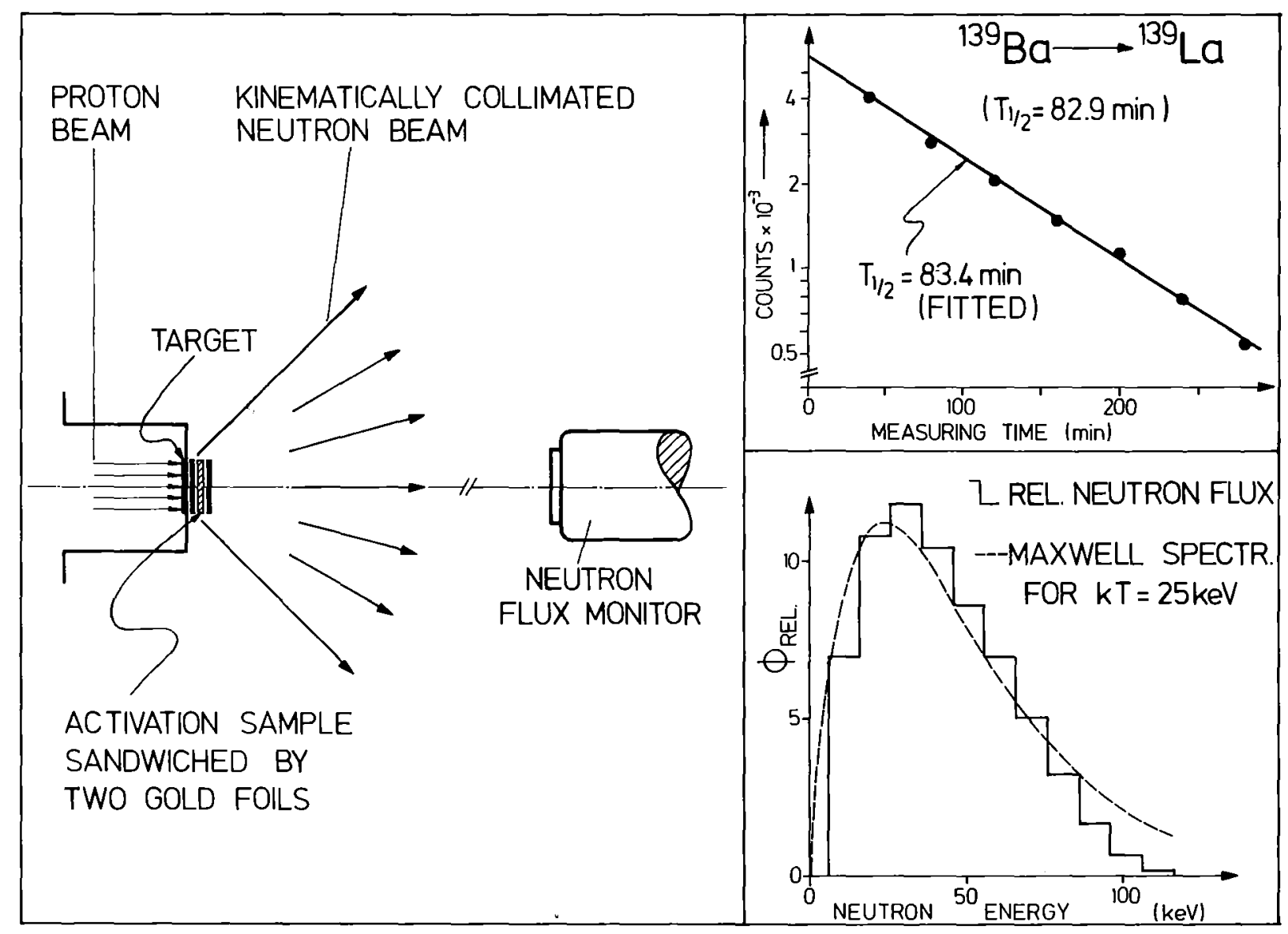

Fig. 1 


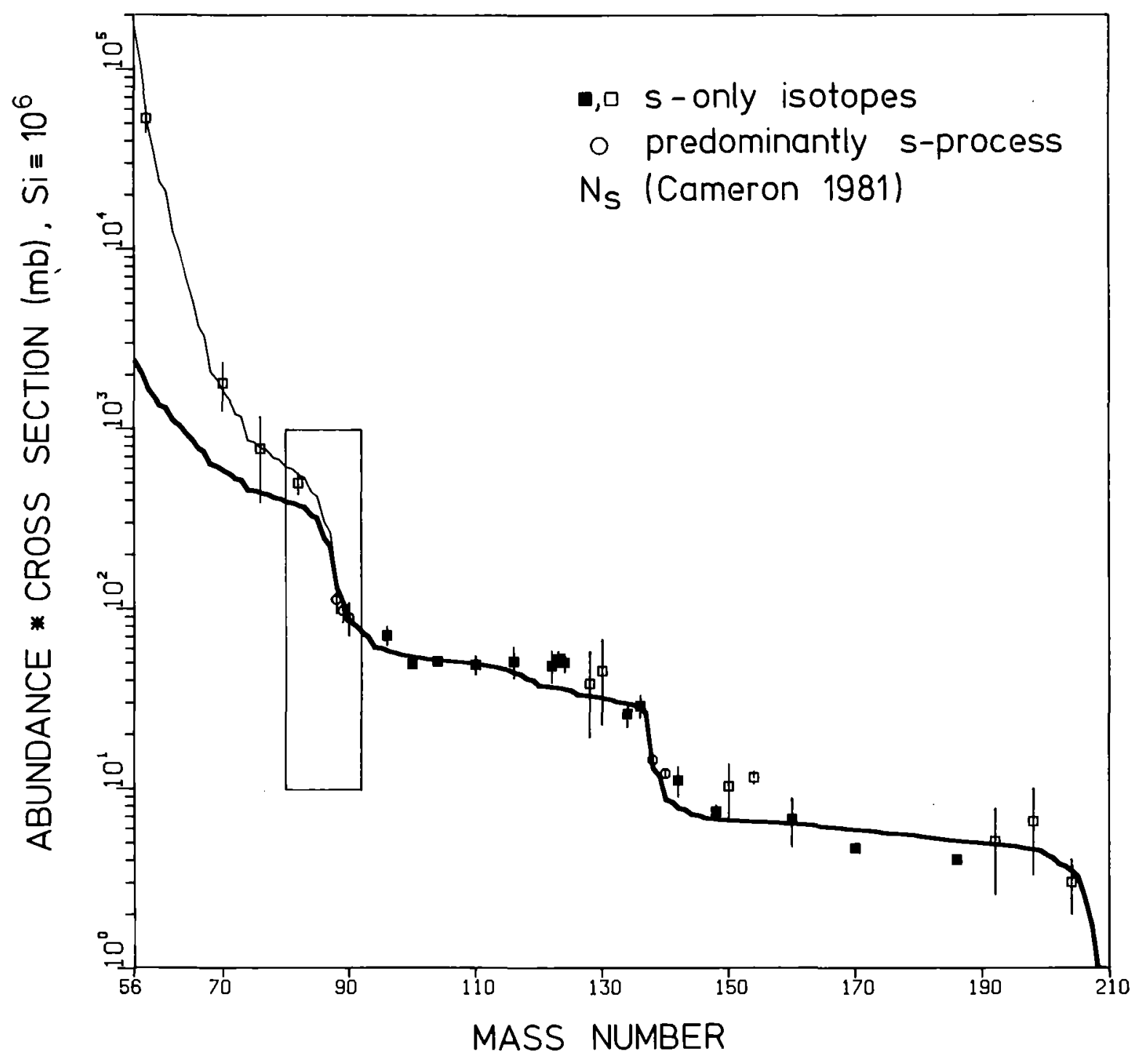

Fig. 2 


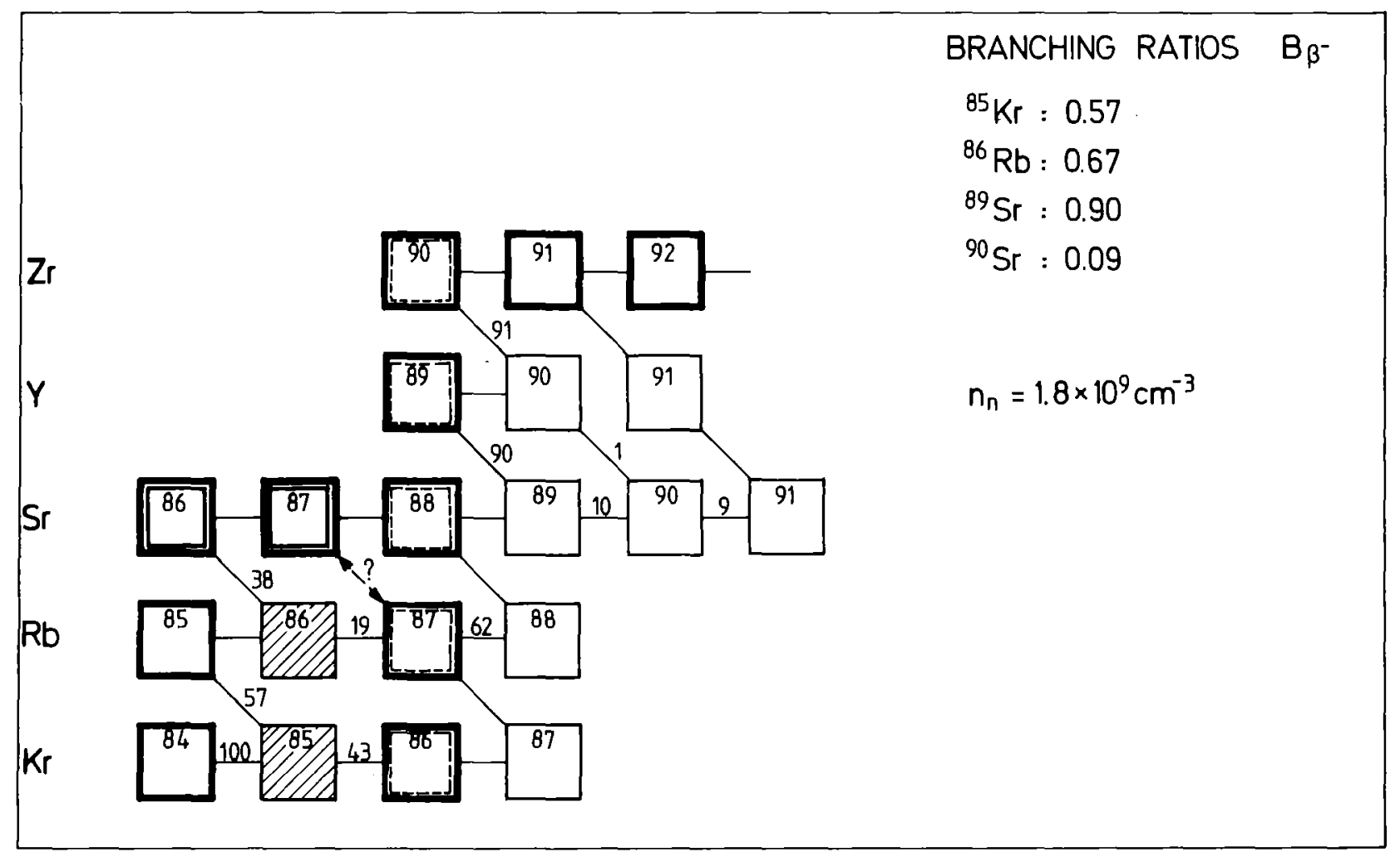

Fig. 3 


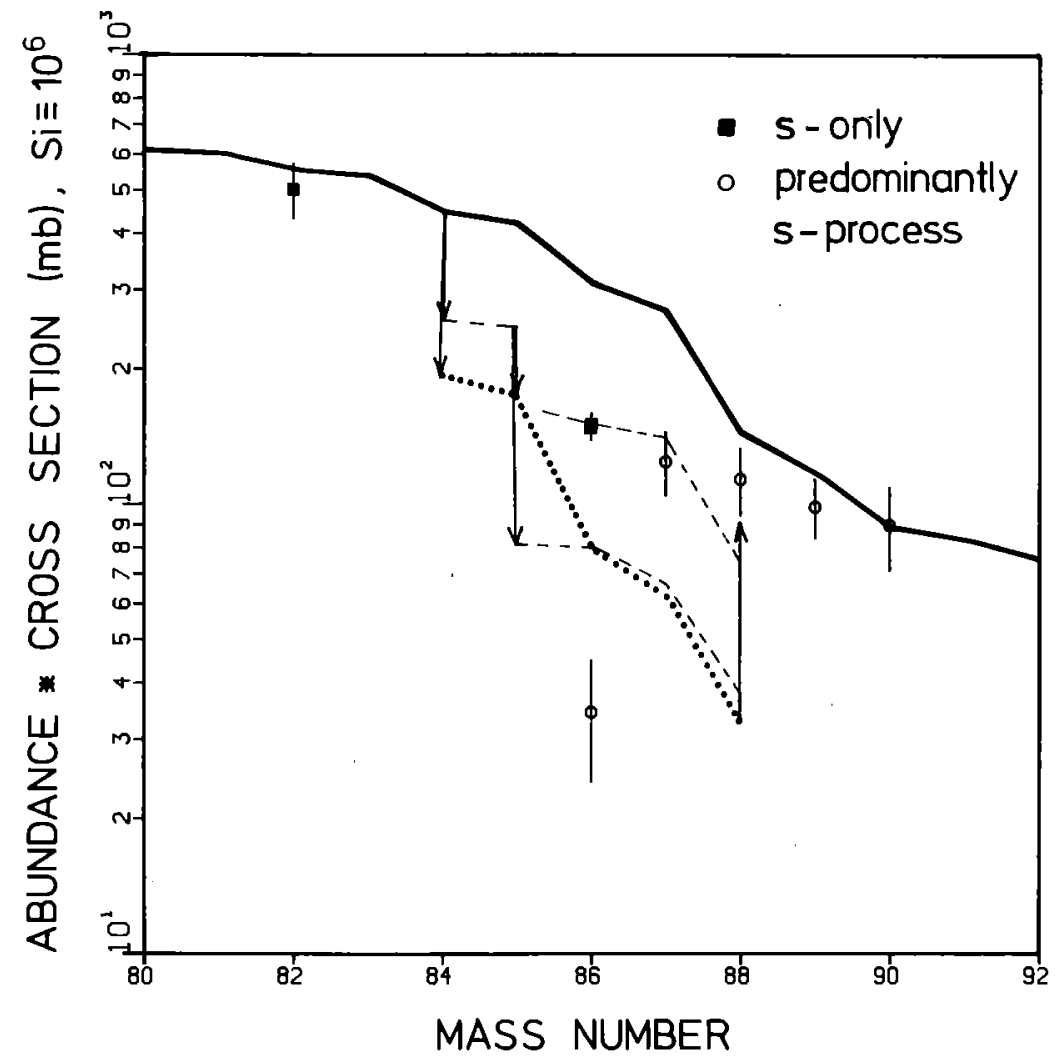

Fig. 4 


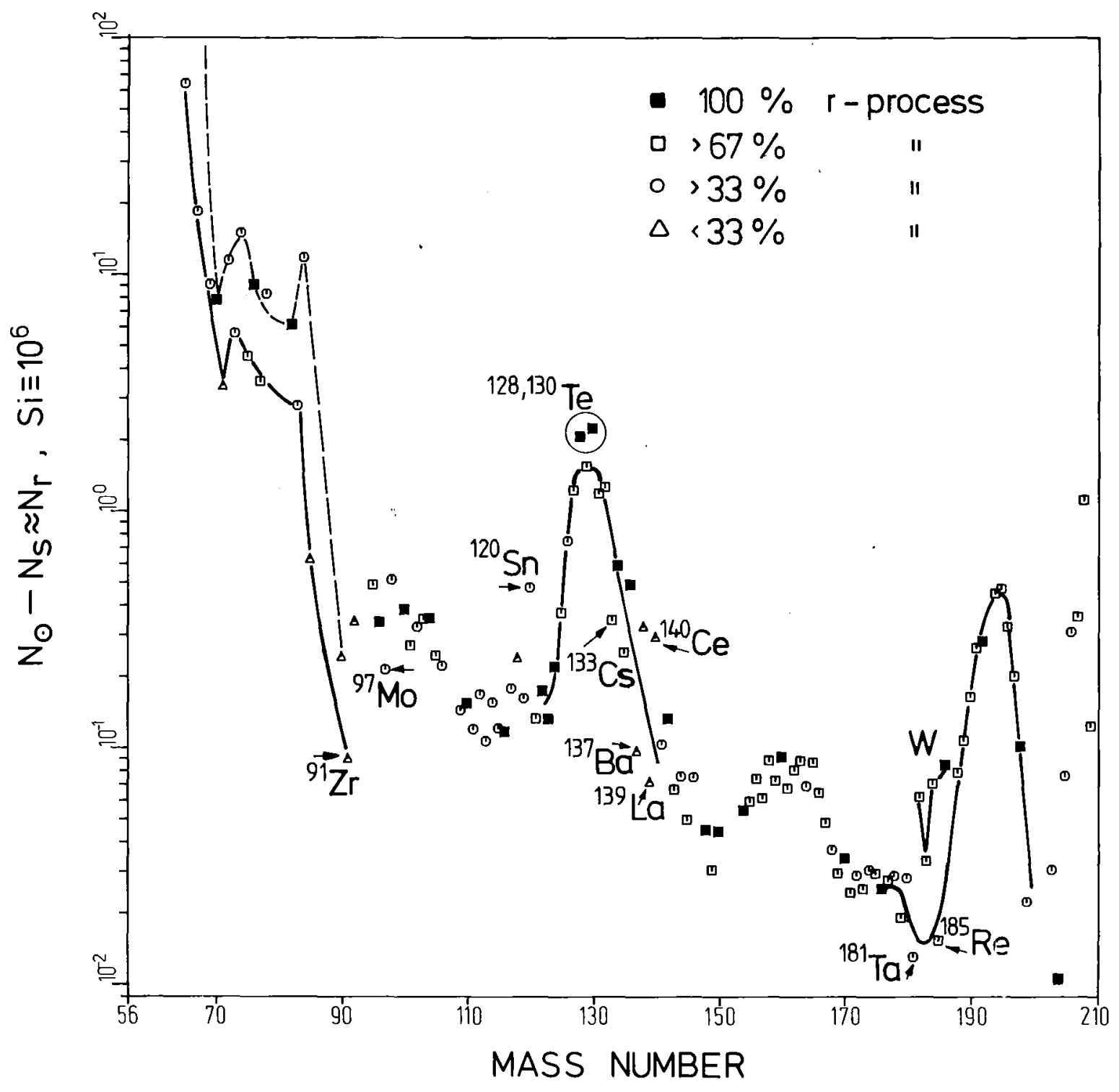

Fig. 5 

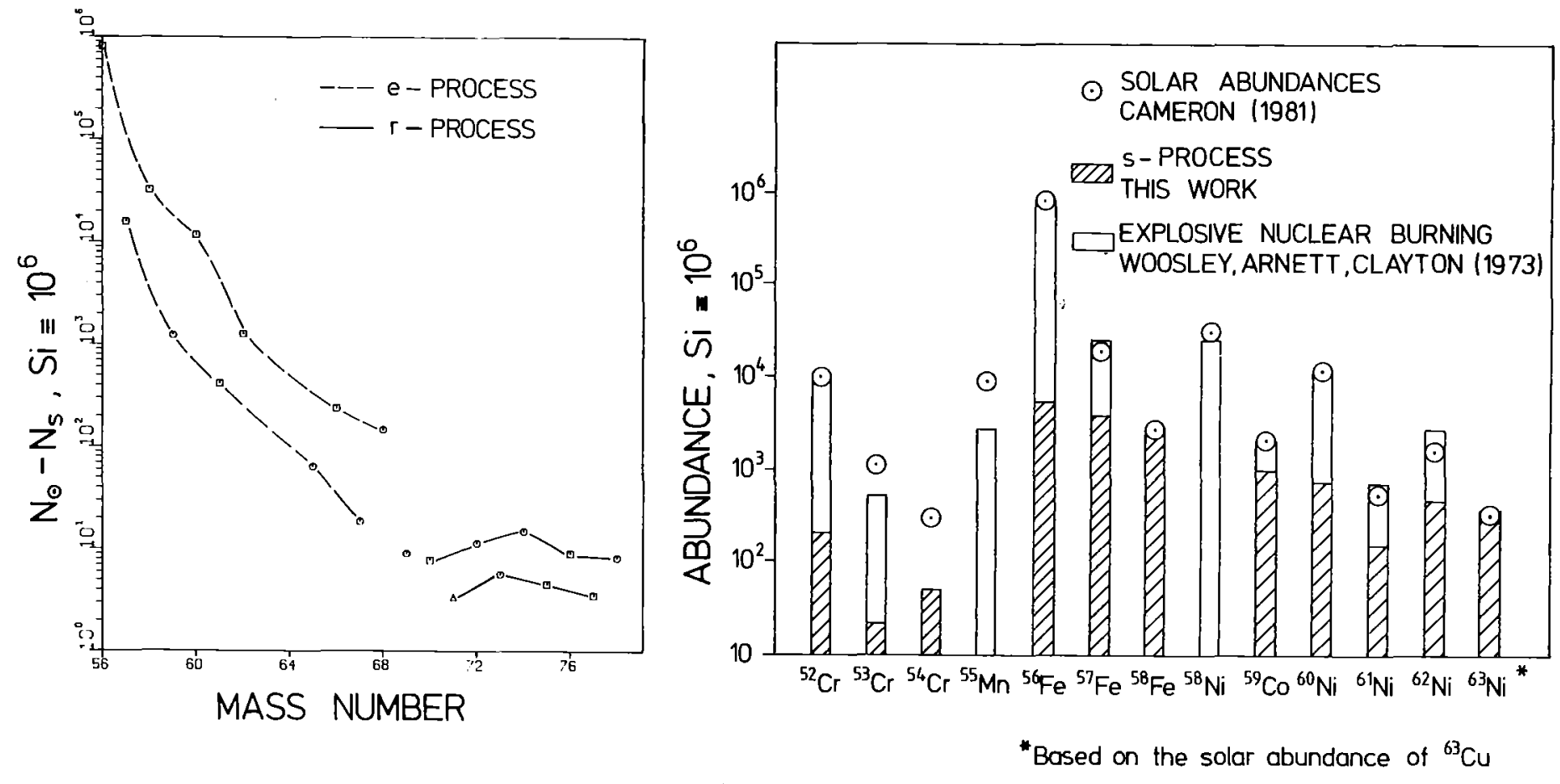

Fig. 6 


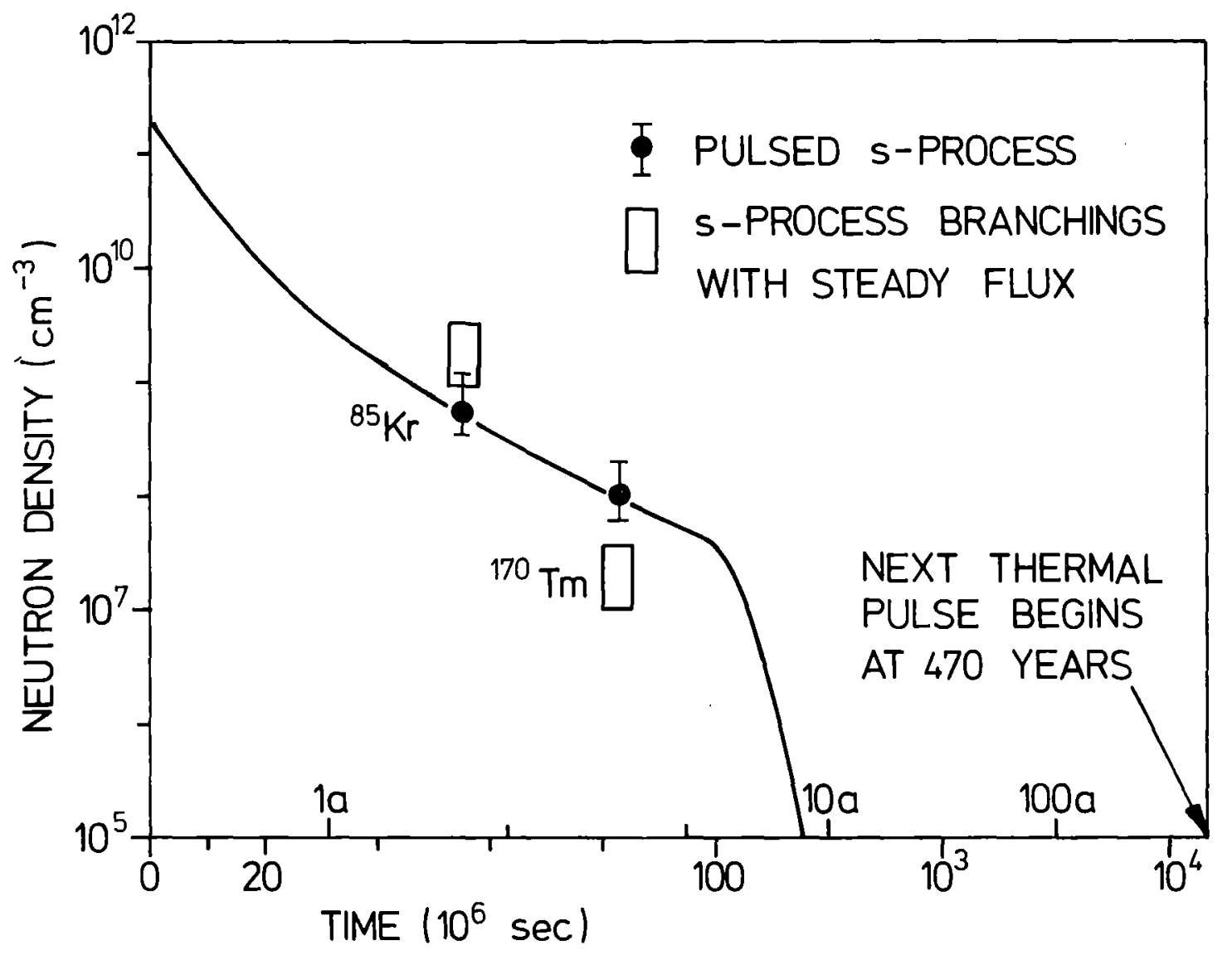

Fig. 7 